\title{
Soybean cyst nematodes: a destructive threat to soybean production in China
}

\author{
Deliang Peng ${ }^{*}$ D, Ru Jiang, Huan Peng and Shiming Liü
}

\begin{abstract}
Soybean cyst nematode (SCN), Heterodera glycines, is one of the most important pests in soybean production worldwide. In China, 11 different races of SCN, including a newly identified race ' $X 12$ ' with super-virulence, have been surveyed and found to be distributed in 22 provinces. Among them, races 1, 3 and 4 are dominant in the two principal soybean-producing areas, Northeast China and Huanghuaihai Valley, causing over 120 million dollars of annual yield loss. Rapid and reliable PCR-based approaches have been developed for the molecular diagnosis of SCN. High-throughput methods for the identification of soybean resistance against SCN are also developed with specific single nucleotide polymorphism markers by using Kompetitive Allele Specific PCR technology. Over 10,000 soybean germplasm sources were evaluated for their SCN resistance, and 28 SCN-resistant soybean accessions were selected to construct an applied core collection, which has been used for soybean breeding in China. Recently, the genome sequences of SCN and soybean are publically available, and two major SCN-resistant genes (rhgl and Rhg4) have been identified in soybean, which greatly facilitate the researches on SCN virulence and soybean resistance, and also soybean resistance breeding against SCN. However, the management of SCN still faces many bottlenecks, for instance, the single resistance genes in soybean cultivars can be easily overcome by new SCN races; the identified resistance genes are inadequate to meet the practical breeding needs; and our understanding of the mechanisms of SCN virulence and soybean resistance to SCN are limited. SCN is a destructive threat to soybean production throughout the world including China. In this review, the major progress on soybean SCN is summarized, mainly focusing on the recent research progress in SCN, soybean resistance to SCN and integrated management of SCN in China, and aiming at a better understanding of the current SCN research status and prospects for future work.
\end{abstract}

Keywords: Soybean cyst nematode, Soybean, Biology, Resistance, Integrated management

\section{Background}

Soybean (Glycine max L.) is an important crop which provides a sustainable source of protein and oil worldwide. China is the 4th largest producer of soybean in the world with 1,750,000 tons of production in 2020. The average soybean yield in China is 1.78 tons per ha, which is lower than those in the three largest soybean producers, the USA, Brazil and Argentina, with 3.47, 3.39 and 2.32 tons per ha, respectively. Soybean cyst nematode $(\mathrm{SCN})$, Heterodera glycines, is a sedentary

\footnotetext{
* Correspondence: dlpeng@ippcaas.cn; smliuhn@yahoo.com

State Key Laboratory for Biology of Plant Diseases and Insect Pests, Institute of Plant Protection, Chinese Academy of Agricultural Sciences, Beijing 100193, China
}

endoparasitic nematode that parasitizes soybean roots. To initiate a parasitic life cycle, SCN secretes a series of effectors mainly through its stylet to soften and degrade host cell walls, and to induce the formation of feeding sites (syncytia) near the vascular cylinder, from which SCN obtains nutrition. The host soybean shows two types of interactions with SCN: incompatible interaction and compatible interaction. In the incompatible interaction, soybean exhibits resistance to SCN and SCN may stop developing at any juvenile stage (J2, J3 or J4); while in the compatible interaction, soybean displays susceptibility to SCN and SCN can complete its entire life cycle in host (Klink et al. 2007a, 2007b, 2009). Generally, the yield is decreased by about $20-30 \%$ in normally SCN-

(c) The Author(s). 2021 Open Access This article is licensed under a Creative Commons Attribution 4.0 International License, which permits use, sharing, adaptation, distribution and reproduction in any medium or format, as long as you give appropriate credit to the original author(s) and the source, provide a link to the Creative Commons licence, and indicate if changes were made. The images or other third party material in this article are included in the article's Creative Commons licence, unless indicated otherwise in a credit line to the material. If material is not included in the article's Creative Commons licence and your intended use is not permitted by statutory regulation or exceeds the permitted use, you will need to obtain permission directly from the copyright holder. To view a copy of this licence, visit http://creativecommons.org/licenses/by/4.0/. 
infested fields, by $60-70 \%$ in severely infested fields, and even by $100 \%$ (i.e., no yields) in some cases. SCN is one of the most devastating pests in soybean production worldwide, causing huge yield losses annually. The annual yield loss reaches over 1 billion dollars in the USA alone (Koenning and Wrather 2010). In China, SCN is also one of the most damaging pests in soybean production, which is broadly distributed in 22 provinces (Zheng et al. 2000, 2009; Wang et al. 2015; Peng et al. 2016a; Song et al. 2016; Long et al. 2017). The annual yield loss caused by SCN in China is more than 120 million dollars (Ou et al. 2008).

Previously, a total of 10 SCN races were detected in China, of which races 1 and 3 are majorly distributed in soybean-producing areas in Northeast China, while race 4 is the dominant race over the Huanghuaihai Valley. Recently, a new race (X12) was identified in China (Lian et al. 2017), which could infect all the tested soybean sources and showed a stronger virulence than race 4 (which had previously been thought the most virulent among all the SCN races). A 2nd population of race $\mathrm{X} 12$ was identified in Hekou Town, Gujiao City, Shanxi Province, China (Lian et al. 2021). The rapid and reliable molecular diagnosis based on PCR was developed for SCN identification. Additionally, some SCN effectors were functionally characterized. Further, based on the genome sequence of an inbred SCN population 'TN10' (http:// www.scnbase.org) that was published recently, a total of 29,769 genes were annotated, of which 431 were identified as putative effectors (Masonbrink et al. 2019). The genome of race X12 was also sequenced and successfully assembled (Lian et al. 2019). Undoubtedly, these will greatly promote research on all aspects of SCN.

Planting resistant soybean cultivars is an effective and environmentally friendly means for $\mathrm{SCN}$ control. In China, over 10,000 soybean germplasm resources have been evaluated for their SCN resistance, and more than 400 soybean accessions have been found to be immune or highly resistant to $\mathrm{SCN}$, of which some accessions showed broad-spectrum resistance to multiple SCN races in the 1990's (Liu et al. 1995). An applied core collection consisting of 28 soybean accessions were selected as the major resistance sources for soybean breeding against SCN (Ma et al. 2006). Many SCN-resistant soybean varieties, such as the 'Kangxian' series, were released to the Chinese market. So far, 216 quantitative trait loci (QTL) have been mapped to underlie SCN resistance on all the 20 chromosomes in soybean (http:// www.soybase.org), and two major SCN-resistant genes, rhg1 (Peking-type rhg1- $a$ GmSNAP18, and PI 88788-type rhg1-b GmAAT, GmSNAP18 and GmWI12) on chromosome 18 and Rhg4 (GmSHMT08) on chromosome 08 were cloned and functionally identified (Cook et al. 2012; Liu et al. 2012, 2017). Based on the genomic information of these resistance genes, and in combination with the KASP (Kompetitive Allele Specific PCR) technology, three specific SNAP markers were developed, and the soybean resistance to SCN was able to be high-throughput identified (Shi et al. 2015b). Great advances were also achieved in investigating the resistance mechanism of soybean against SCN. Both GmSNAP18 and GmSHMTO8 are required, with the involvement of GmPR08-Bet VI, to simultaneously contribute to the resistance of Peking-type soybeans to SCN (Meksem et al. 2001; Liu et al. 2012, 2017; Lakhssassi et al. 2020). Multiple copies of the resistance genes were required to ensure SCN resistance in soybean (Cook et al. 2012, 2014; Lee et al. 2015, Yu et al. 2016; Patil et al. 2019). The GmSNAP18 in rhg1 played an important role in the resistance to SCN (Bayless et al. 2016, 2018; Dong et al. 2020), and the one-carbon metabolism via GmSHMT08 might be involved in the resistance (Liu et al. 2012; Karosick et al. 2020). The salicylic acid (SA) and jasmonic acid (JA) signaling pathways and DNA methylation might also be involved in the resistance of soybean to SCN (Lin et al. 2013; Cook et al. 2014; Rambani et al. 2015, 2020; Guo et al. 2019).

Besides planting soybean resistant cultivars, the management of SCN also depends on crop rotation, application of chemical nematicides and using cover crops. Recently, biological control has received increasing attention. In China, over 2000 fungal strains have been screened for their nematicides activities, and many strains including fungi and bacteria have been identified to be effective for the control of SCN. A series of biocontrol products, such as 'Junxianke', were developed and applied (Yuan et al. 2020). A set of integrated SCN management strategies have been established for small farms, large farms and cooperative farms in China.

Here, we review the recent major progress made in $\mathrm{SCN}$, soybean resistance to $\mathrm{SCN}$ and integrated management of SCN, in particular, the summarization of the detailed progress in each aspect mentioned above in China, to the best of our knowledge.

\section{SCN occurrence, distribution and damage}

$\mathrm{SCN}$ is a soil-dwelling endoparasitic nematode that exhibits heteromorphism and amphigony (Singh et al. 2013). This nematode was first discovered in Northeast China in 1899 (Liu et al. 1997), and was subsequently introduced to a number of countries through exportation, including the USA, Columbia, Canada, Brazil, Argentina, the Russian Far East, Indonesia, Egypt, Indonesia, Japan and Korea (Subbotin et al. 2001; Chitwood 2003; Wang et al. 2004). Once SCN occurs in one location, the nematodes can quickly spread to nearby soybean-producing areas. In China, in the 1930s, SCN only occurred in a few places, and until the 1940s, SCN was still restricted 
in the Northeast and the Huanghuaihai Valley, the two principal soybean production areas in China. However, thus far, it has been detected in 22 provinces/municipalities of China: Heilongjiang, Liaoning, Jilin, Inner Mongolia Autonomous Region, Hebei, Henan, Beijing, Shandong, Shanxi, Anhui, Shaanxi, Jiangsu, Hubei, Shanghai, Zhejiang, Guangxi, Guizhou, Yunnan, Jiangxi, Gansu, Ningxia and Xinjiang Uygur Autonomous Region (Zheng et al. 2000, 2009; Wang et al. 2015; Peng et al. 2016; Song et al. 2016; Long et al. 2017; Luo et al. 2019).

The whole life cycle of SCN includes egg, three juvenile (J2, J3 and J4) and adult (female and male) stages. No unusual biological differences have been shown in SCN between the populations in China and those in the rest of the world. SCN can infect only a relatively narrow range of hosts. The main hosts are all leguminous plants, including soybean, mungbean, green pea and numerous types of edible beans. SCN can also damage nonleguminous plants in China, such as Rehmannia glutinosa, Paulownia fortune, sesame (Sesamum indicum), tobacco (Nicotiana tabacum) and tomato (Peng et al. 1999).

After infection by SCN, soybean exhibits a series of symptoms. Above the ground, the plants show growth retardation, stunting, yellowing of the cotyledons and true leaves, and chlorosis. The seriously infected seedlings stop growing, eventually leading to death (Fig. 1a). The flower buds are clustered, the internodes are shortened, the flowering time is delayed, the pods cannot be set or only few pods are set, and the leaves become yellow. Sometimes, large areas of seriously infected soybean fields become so yellow and withered that it looks as if they were on fire, so SCN disease is also called 'Fire Dragon Yangzi'. Under the ground, the main roots and lateral roots develop poorly, but the number of fibrous roots is increased. As a result, the whole root system presents hair-like fibrous roots. The number of nitrogen-fixing nodules is reduced. Also, the swollen and white to cream-colored SCN females (Fig. 1b) can be observed on the infected lateral roots four to six weeks after planting.
SCN has become one of the most economically important pathogens of soybean worldwide, posing a serious threat to sustainable soybean production, and causing devastating soybean yield losses annually (Koenning and Wrather 2010; Kim et al. 2016; Peng et al. 2016). The annual yield loss caused by SCN was estimated at more than 1 billion dollars in The United States alone (Koenning and Wrather 2010). SCN is also the most severe pest of soybean in China, resulting in an annual yield loss of more than 120 million dollars (Ou et al. 2008).

\section{SCN species, races and HG types}

Since Heterodera sojae was first reported in soybean in Korea (Kang et al. 2016), this nematode has also been found in soybean roots and rhizosphere soil in Wuyuan, Jiangxi Province, China, as a newly recorded species in China (Zhen et al. 2018). Therefore, there are now two species of soybean cyst nematodes $(H$. glycines and $H$. sojae) damaging soybean. $H$. sojae can infect 10 crops: soybean, jequirity, cowpea, pea, lentil, mungbean, adzuki bean, sword bean, green beans and alfalfa. However, $H$. sojae can complete its life cycle only in soybean. Among 40 soybean cultivars evaluated for resistance to $H$. sojae, 19 were highly susceptible, 11 were moderately susceptible, 5 were moderate resistant, and 5 were highly resistant (Zhen et al. 2018).

The complete characterization of the race scheme was developed for $H$. glycines based on the phenotypic responses of soybean to four host differentials ('PI 548402' ('Peking'), 'Pickett', 'PI 88788' and 'PI 90763'). Accordingly, a total of 16 races were designated (Riggs and Schmitt 1988). Subsequently, an HG type test was developed on the basis of the resistance of SCN to seven indicator lines (Peking, PI 88788, PI 90763, 'PI 437654', 'PI 209332', 'PI 89772' and 'PI 548316 (Cloud)) (Niblack et al. 2002). In 1984, two SCN races (races 1 and 3) were first reported in Northeast China, of which SCN race 1 occurred in Liaoning Province and Jilin Province, while SCN race 3 was found in Heilongjiang Province and Jilin Province, east of Liaoning Province, and Inner Mongolia

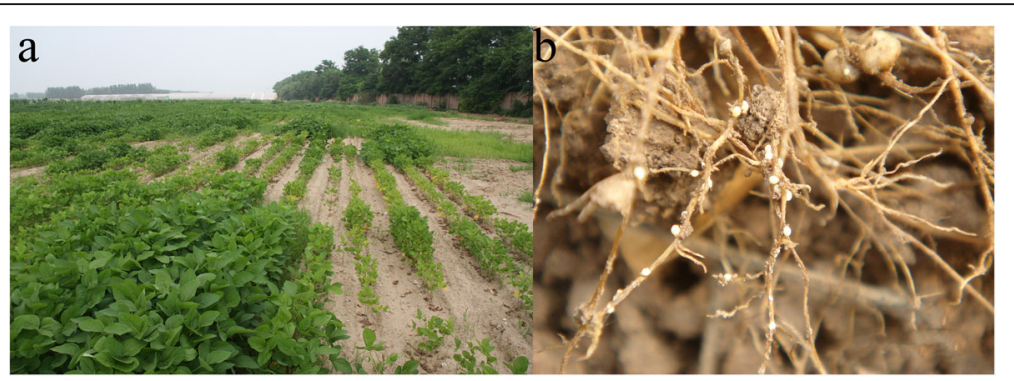

Fig. 1 A soybean field severely infected with soybean cyst nematode (SCN, Heterodera glycines) (a), and white females of SCN on an infected soybean root $(\mathbf{b})$ 
Autonomous Region. After that, SCN races 2, 4, 5 and 7 were identified in Shandong Province, the Yellow River Valley, Anhui Province and Shandong Province, respectively (Chen et al. 1987; Liu et al. 1995). To date, 11 SCN races $(1-7,9,13,14$ and X12), and 9 HG types $(0,7,2.7$, 5.7, 1.3.7, 2.5.7, 1.2.5.7, 1.3.4.7 and 1.2.3.5.7) have been reported in China (Lian et al. 2017). The increased virulence of SCN has been observed in recent years, and the dominant races appear to be shifting in China (Lian et al. 2017; Hua et al. 2018). To some extent, this indicates the impact of ecological environment on the evolution of virulence in nematode, which is a serious threat to agro-ecology and agricultural production.

The SCN race X12 was recently isolated and identified from a heavily SCN-infected soybean field in Xingjiashe of Gujiao City, Shanxi Province, China. This race is able to successfully parasitize all SCN-resistant soybean germplasm sources tested thus far, including the four differentials (Peking, Pickett, PI 88788 and PI 97603) of the race scheme, the seven indicator lines used for the HG type test, and also 'ZDD2315' ('Huipizhiheidou'), the most promising elite resistant germplasm in China. Indeed, except for the newly identified $\mathrm{SCN}$ race X12, ZDD2315 is resistant to all the SCN populations identified so far (Lian et al. 2017). PI 437654, which is vulnerable to few natural SCN populations, is another elite resistant germplasm from the United States. X12 has become a potentially serious threat to the soybean production in China. Since X12 shows a super-virulence, even stronger than $\mathrm{SCN}$ race 4 , it is estimated that there are new or additional virulence effectors in X12. Recently, the second population of race X12 was found in Hekou Town, Gujiao City, Shanxi Province, China (Lian et al. 2021). Both X12 populations were detected at different locations within a city, suggesting that X12 is spreading slowly, but even so, it should be documented in great detail. It is not yet known how and why the new race $\mathrm{X} 12$ was formed and spread in the city. The highly toxic SCN race 4 occurs at a serious level in Shanxi Province in China, and therefore it has been proposed that X12 might have evolved from race 4 under conditions suitable for SCN propagation, including suitable soil and climate conditions, and also the lack of SCN-resistant cultivars in this city (Lian et al. 2021).

\section{SCN genome}

The genetic map of SCN with 10 linkage groups was reported in 2005 (Atibalentja et al. 2005). A draft genome of an inbred SCN H. glycines population TN10 (Hg type 1.2.6.7) was recently published (Masonbrink et al. 2019). The 738 identified contigs were assembled into $123 \mathrm{Mb}$, and 29,769 genes were annotated (Masonbrink et al. 2019; http://www.scnbase.org). Lian et al. (2019) applied PacBio sequencing and $\mathrm{Hi}-\mathrm{C}$ to assemble the genome of the new race X12 (Hg type 1.2.3.4.5.6.7). Using whole genome shotgun (WGS) sequencing, Illumina pairedend sequencing, Pacific Biosciences (PacBio) sequencing, $10 \times$ Genomics linked reads and high-throughput chromatin conformation capture $(\mathrm{Hi}-\mathrm{C})$ genome scaffolding techniques, a $141.01 \mathrm{Mb}$ assembled genome was obtained with scaffold and contig N50 sizes of $16.27 \mathrm{Mb}$ and $330.54 \mathrm{~Kb}$, respectively. Using de novo, homolog and RNAseq data generated from eggs, J2, J3 and J4 of race $\mathrm{X} 12$, a total of 11,882 genes were predicted, and $79.0 \%$ of homologous sequences were annotated in the genome (Lian et al. 2019). Obviously, both the estimated genome size and the numbers of annotated genes were significantly different between two races X12 and TN10 (Lian et al. 2019; Masonbrink et al. 2019). For the TN10 genome, those contigs were not successfully assembled into chromosomes (Masonbrink et al. 2019), while the X12 genome obtained was a chromosome-level genome (Lian et al. 2019). However, all these high-quality TN10 and X12 genome data will provide extremely valuable information for further investigation of SCN at molecular level, including SCN-plant interaction and co-evolution, molecular breeding, and also the molecular mechanism underlying the high virulence of X12.

\section{SCN diagnosis}

SCN $H$. glycines belongs to the schachtii group, which includes various species only differing in minor morphological and morphometrical characters (Subbotin et al. 2001). Traditional diagnosis of this group of cyst nematodes, based on morphology and morphometrics, is time-consuming and difficult, even for taxonomists. In practice, the cyst-forming nematodes are assumed to be SCN H. glycines if they are found in infested field with a soybean planting history (Riggs and Niblack 1993).

PCR-based diagnostics provides an attractive solution for rapid SCN identification. One or several species in a mixed population can be detected by a single PCR with specific primer combinations or multiplex PCR. This technology has been widely applied in nematology for the diagnosis and identification of various agricultural nematodes, such as Globodera pallida and G. rostochiensis (Subbotin et al. 2001), Bursaphelenchus xylophilus (Kikuchi et al. 2009), Radopholus similis (Peng et al. 2012a), Heterodera filipjevi (Peng et al. 2013) and Meloidogyne hapla (Peng et al. 2017).

To distinguish $H$. glycines from other cyst nematodes, PCR amplification with 12 RAPD primers was performed, which produced 169 bands. Using the primer OPA06 produced clear bands that visibly distinguished $H$. glycines from the other 10 cyst nematodes tested. After sequencing the specifically amplified OPA06477 fragment, a specific SCAR primer set, SCNFI/SCNRI, was designed for $H$. glycines. Using SCNFI (5' -GGACCC 
TGACCAAAAAGTTTCCGC-3') and SCNRI (5'GGACCCTGACGAGTTATGGGCCCG-3'), a fragment of 477-bp was amplified by PCR. As the positive control, duplex PCR amplification was designed using the universal primers D2A/D3B with a single amplified fragment of $800 \mathrm{bp}$ for all the isolates. The amplified fragment using this set of universal primers indicates the presence of nematode DNA template in samples to avoid false negative results. The SCAR primer set was successfully used in direct, fast and reliable PCR assays to diagnose SCN H. glycines. The SCAR markers can be amplified from genomic DNA of a single J2 or female nematode (Ou et al. 2008).

To discriminate $H$. glycines from $H$. avenae, on the basis of the previously identified RFLPs and the sequences of rDNA-ITS regions of Chinese $H$. glycines and $H$. avenae populations (Zheng et al. 2000), a duplex PCR was conducted. The species primer GlyF1 (5' -TTACGG ACCGTAACTCAA-3') was specifically designed for $H$. glycines, and a universal primer rDNA2 (5'-TTTCACTC GCCGTTACTAAGG-3') was combined with GlyF1 to form a primer set, resulting in a specific amplicon of $1811 \mathrm{bp}$. Another primer set, the universal D3A primer (5'-GACCCGTCTTGAAACACGGA-3') and D3B primer (5'-TCGGAAGGAACCAGCTACTA-3'), was used as the positive control with an amplified fragment of 345 bp (Peng et al. 2001; Subbotin et al. 2001).

However, we need to modify the current molecular diagnosis technology and develop a RPA (Recombinase Polymerase Amplification) assay and test strip technique, and also a real-time PCR technique to quantify SCN in soils for providing practical recommendations to the growers.

\section{SCN effectors}

Effectors are the key for nematodes to parasitize their plant hosts (Juvale and Baum 2018; Vieira and Gleason 2019). In total, 431 putative effectors were identified in the SCN genome (Masonbrink et al. 2019). However, only a few effectors have been functionally characterized. The pectate lyases are known to play a key role in pectin degradation by catalyzing the random cleavage of internal polymer linkages (endo-pectinases). de Boer et al. (1996) reported two putative pectate lyase genes ( $\mathrm{Hg}$ pel-1and $\mathrm{Hg}$-pel-2) that are expressed in the subventral esophageal glands of $H$. glycines. RNAi silencing of the pectate lyase gene, $h g$-pel, in $H$. glycines caused a change in sexual fate, which favored male development on roots (Bakhetia et al. 2007). The pectate lyases have been identified in several sedentary plant parasitic nematodes (PPNs), such as species of Heterodera, Globodera and Meloidogyne (Popeijus et al. 2000; Peng et al. 2012b). A pectate lyase gene, $\mathrm{Hg}$-pel-5, was cloned from $\mathrm{H}$. glycines. $\mathrm{Hg}$-pel-5 encodes a protein of 227 amino acids, which was found to be accumulated in the subventral esophageal gland cells of $\mathrm{H}$. glycines. The $\mathrm{Hg}$-pel-5 transcripts were mainly expressed at the preJ2 and early parasitic J2 stages (Peng et al. 2012b). Subsequently, four other pectate lyase genes named $\mathrm{Hg}$-pel-3, $\mathrm{Hg}$-pel-4, $\mathrm{Hg}$ pel-6 and $\mathrm{Hg}$-pel-7, were cloned from $\mathrm{H}$. glycines and characterized. The predicted protein sequences of HGPEL-3, HG-PEL-4 and HG-PEL-6 differed significantly from three previously reported pectate lyases of $H$. $g l y$ cines (HG-PEL-1, HG-PEL-2 and HG-PEL-7) in both amino acid sequences and genomic structures. Phylogenetic analysis revealed that the pectate lyases of $\mathrm{H}$. glycines were clustered into distinct clades, and they might have evolved from at least two ancestral genes. Furthermore, multiple $\mathrm{Hg}$-pel-6-like genes were presented in the $H$. glycines genome. Four pectate lyases (Hg-pel-3, Hg-pel-4, Hg-pel-6 and Hgpel-7) were actively accumulated in the subventral esophageal gland cells, and their corresponding genes were strongly expressed at the egg, pre J2 and early parasitic J2 stages. These proteins play a role in the migratory phase of the nematode life cycle. Knockdown of $\mathrm{Hg}$-pel-6 by in vitro RNA interference resulted in a $46.9 \%$ reduction in $\mathrm{J} 2$ numbers and a $61.5 \%$ decrease in female numbers of $H$. glycines in the infected plants (Peng et al. 2016b). All these results suggest that two types of pectate lyases are present in the $H$. glycines genome and may play different roles during infection.

The expanded protein (expansin) is secreted through the stylet of nematodes. Two expansin genes ( $H g$-exp-1 and $H g$-exp-2), which encode proteins of 288 and 295 amino acids, respectively, were successfully identified from the J2s of $\mathrm{H}$. glycines. Both predicted proteins contain a signal peptide at the $\mathrm{N}$-terminal, and have no any predicted transmembrane domains. They were expressed in the subventral esophageal gland cells of $H$. glycines. After RNAi silencing of $H g$-exp-1, the numbers of $J 2 \mathrm{~s}$ and females in soybeans were decreased by 38.3 and $43.4 \%$, respectively. The important roles of these two expansin genes in the early parasitic process of $\mathrm{H}$. glycines have been clarified (Zhang et al. 2018).

Two new lysozyme genes ( $H g$-lys 1 and $H g$-lys2) were cloned from $\mathrm{SCN}$ and further characterized. The transcripts of both $H g$-lys 1 and $H g$-lys 2 were accumulated in the intestine of SCN. Both $H g$-lys 1 and $H g$-lys 2 were upregulated when the SCN J2s were exposed to the Grampositive bacteria Bacillus thuringiensis, Bacillus subtilis or Staphylococcus aureus. Knockdown of these two lysozyme genes by in vitro RNA interference caused a significant decrease in the survival rate of SCN. Thus, the lysozyme is very important for the survival and defense of SCN (Wang et al. 2019).

The effector Hg16B09 was functionally characterized via soybean hairy root transformation, and the results verified that Hg16B09 enhances the susceptibility of 
soybean to $\mathrm{SCN}$, so it is a virulent $\mathrm{SCN}$ effector $(\mathrm{Hu}$ et al. 2019).

Recently, by single-nematode sequencing, 48 differentially expressed genes (DEGs) encoding putative effectors were identified in the three SCN contrasts: Peking ${ }_{\text {vir }}$ vs Avr, Peking vir vs PI $88788_{\text {vir }}$, and PI $88788_{\text {vir }}$ vs Avr. In particular, the selection of virulent SCN individuals on Peking led to a distinctly altered transcriptome. Among the identified putative DEGs, 5 were consistently expressed among all the three contrasts, 4 of which (Hetgly.G000017083, Hetgly.G000017105, Hetgly.G000025902 and Hetgly.G000028833) encoding a putative gland protein G17G01, a SRCR, pectin-lyase and lectin-like domains-containing protein, and two dorsal gland proteins, respectively, were all down-regulated in Peking-virulent (Peking ${ }_{\text {vir }}$ ) individuals. The downregulation of SCN genes may be associated with the initiation of ETI (effector-triggered immunity) in the host in response to nematode infection. However, the transcriptome of virulent SCN individuals on PI 88788 was similar to avirulent ones except for a few genes, suggesting a different virulence strategy of SCN to Peking (SteCroix et al. 2021). All these indicate the importance of effectors on SCN virulence.

\section{SCN-resistant soybean germplasm resources and cultivars}

Planting resistant soybean varieties is an effective and environmentally friendly means for the control of SCN. It is a top priority to screen more resistant germplasm sources and breed more resistant cultivars. In China, during 1986-1992, the Coordinative Group of Evaluation (CGE) of Soybean Cyst Nematode organized Chinese scientists to test and evaluate soybean germplasm resources for their resistance against SCN. The evaluation and grading standard of resistance was taken as follows: immune (without any cysts in plants), highly resistant (with 0.1-3.0 cysts per plant), moderately resistant (with 3.1-10.0 cysts per plant), susceptible (with 1130.0 cysts per plant), and highly susceptible (with more than 30.1 cysts per plant) (CGE 1993). More than 10,000 accessions of soybean germplasm were evaluated for their resistance to $\mathrm{SCN}$ races 1,3 and 4. Among them, 128 soybean accessions were resistant to $\mathrm{SCN}$ race 1 (including 16 accessions with immunity to race 1); 288 accessions were resistant to $\mathrm{SCN}$ race 3; and 30 accessions showed immunity to, and 11 accessions were resistant to SCN race 4. Notably, four accessions ('Wuzaiheidou', 'Huipizhiheidou', 'Longraodaheidou' and 'Wupuheidou') were resistant to all these three SCN races (CGE 1993; Liu et al. 1995). Subsequently, the distribution and phenotypes of 432 immune or highly resistant Chinese accessions were surveyed, and a general core collection was established using a range of sampling methods (Cui et al. 2003). Prior to 2006, in China, a primary core collection containing 149 entries was selected following a survey of the distributions and phenotypes of $432 \mathrm{SCN}$ immune or highly resistant Chinese accessions. Finally, 28 accessions containing eight bred lines and 20 landraces from 12 provinces were selected to construct the applied core collection. This collection consisted of seven immune and 21 highly resistant accessions, of which four accessions were resistant to the three SCN races, two accessions were resistant to two $\mathrm{SCN}$ races and the others were only resistant to a single $\mathrm{SCN}$ race. These resistant accessions were derived from 12 provinces, including Heilongjiang Province (2), Jinlin Province (2), Liaoning Province (1), Heibei Province (3), Shanxi Province (10), Shaanxi Province (2), Shandong Province (2), Jiangsu Province (1), Anhui Province (1), Jiangxi Province (1), Hubei Province (1), Hunan Province (1) and Guizhou Province (1) (Ma et al. 2006). Since then, many additional soybean resources and cultivars have been tested for their SCN resistance, and many new SCN-resistant resources and cultivars have been identified (Liu et al. 2008, 2015; Kong et al. 2012; Li et al. 2013; Han et al. 2015). Li et al. (2017) tested 779 soybean germplasm sources for their resistance to SCN race 3 by a pot experiment, using infected soil cultivated with soybean plants during 2006-2014. Among them, 19 resistant germplasm sources showed resistance to SCN race 3, including 'Fengyuan 001-3', 'W93155', 'Jihuang 229', 'Hejiao 01-1900', 'W94128-8', 'YX04-6561', 'W7491', 'W201 102-25', 'Qihuang 30', 'Qihuang 31', 'Kangxian 6', 'Kanxian 7', 'Bainong 9', 'CM2008-12', 'Jiyu 407', 'Qihuang32', 'Qihuang 28', 'Qihuang 33' and 'BN10'. These varieties (lines) could be used as the SCNresistant parents for breeding.

In the USA, Guo et al. (2006) identified a broadspectrum source, 'PI 404198A', which conferred resistance to races 1, 2 and 5. Jiao et al. (2015a) discovered that 'PI $437655^{\prime}$ conferred broad-spectrum resistance to SCN, which was also resistant to SCN LY2. Arelli et al. (2015) screened 100 new soybean accessions and identified 67 accessions conferring resistance to SCN races 2, 3 or both. Among them, due to the yellow seed-coat and resistance to both $\mathrm{SCN}$ races 2 and 3, 17 accessions might be the good germplasm sources for breeding. Additionally, some SCN-resistant accessions, such as PI 437654 and 'PI 567516C', still conferred resistance to other nematodes such as root-knot nematode Meloidogyne incognita and reniform nematode (Rotylenchulus reniformis) (Ha et al. 2007; Jiao et al. 2015a).

The SCN resistance of the commercial soybean varieties is mostly derived from three accessions: PI 88788, PI 209332 and Peking (about 90\%) (Winter et al. 2006). Both PI 437654 and Huipizhiheidou are also good sources of SCN-resistant germplasm conferring broad- 
spectrum resistance to almost all of the $\mathrm{SCN}$ races, and were utilized to breed some SCN-resistant cultivars such as Hartwig (Anand 1992). According to the statistics, around $90 \%$ of varieties were bred using PI 88788 as the SCN-resistant source in the central US. However, due to long-term planting of the cultivars which just carry single SCN-resistant resources, such as PI 88788, virulent nematode populations have been developed on most known resistant sources (Mitchum et al. 2007; Colgrove and Niblack 2008; Mitchum 2016). During the longterm incompatible interaction between resistant host soybeans and SCN, the soybeans gradually become domesticated under the selection pressure and then partially, or even entirely, lose their resistance. The soybean source Peking, conferring resistance to SCN races 1,3 and 5, showed moderate susceptibility to a SCN population continuously selected on a resistant soybean line (RIL ExF67). In contrast, it still displayed resistance to the SCN population that was continuously selected on a susceptible line (RIL ExF63) for about 60 generations over 5 years (Kandoth et al. 2017). Clearly, it is essential to endlessly screen and identify new resistant sources, and to breed and plant new resistant cultivars derived from different resistant resources for the long-term management of this nematode.

\section{QTL underlying SCN resistance mapped in soybean}

The resistance of soybean to $\mathrm{SCN}$ is very complicated and controlled by multiple genes (QTL). So far, 216 QTL were mapped to underlie SCN resistance in soybean, and these QTL are distributed on all 20 chromosomes (http://www.soybase.org). However, many QTL were not consistently mapped. The cqSCN-001 (rhg1) on chromosome 18 (Concibido et al. 1994, 1997; Webb et al. 1995; Meksem et al. 2001; Yue et al. 2001, Glover et al. 2004; Guo et al. 2006) and cqSCN-002 (Rhg4) on chromosome 08 (Concibido et al. 1994; Webb et al. 1995; Mahalingam and Shorupska 1995; Meksem et al. 2001; Guo et al. 2005, 2006) are the most important QTL underlying SCN resistance in soybean. They have been consistently mapped in a number of SCN-resistant sources and are thought to be the two major QTL controlling SCN resistance in soybean (Concibido et al. 2004). Meanwhile, the cqSCN-003 on chromosome 16 (Concibido et al. 1996, 1997; Glover et al. 2004), cqSCN005 on chromosome 17 (Kazi et al. 2010), cqSCN-006 on chromosome 15 and cqSCN-007 on chromosome 18 (Wang et al. 2001; Winter et al. 2007; Kim et al. 2011; Kim and Diers 2013; Yu and Diers 2017), qSCN10 on chromosome 10 and qSCN18 on chromosome 18 (Vuong et al. 2010, 2015; Usovsky et al. 2021; Zhou et al. 2021), FGAM1 on chromosome 18 (Bao et al. 2014), two new QTL on chromosomes 18 and 20 in PI 437655 (Jiao et al. 2015b), and $r h g 2$ on chromosome 11 (Suzuki et al. 2020) were genetically mapped.

In addition, many other important QTL have been mapped in some soybean sources underlying resistance to multiple SCN races. Guo et al. (2005) mapped six QTL on chromosomes 8,11, 15, 16, 18 and 19 in PI 97603, with resistance to $\mathrm{SCN}$ race 3, races 2 and 5, race 5 , races 2 and 3, races 2,3 and 5, and race 3, respectively. Guo et al. (2006) continued to map four QTL on chromosomes 3, 8, 11 and 18 in 'PI 404198A', conferring resistance to $\mathrm{SCN}$ race 5 , race 1 , races 1 and 5 , and races 1, 2 and 5, respectively. Winter et al. (2007) mapped three QTL on chromosomes 9, 10 and 20 in 'PI 464925B'. In PI 437654, eight QTL were mapped on chromosomes $1,4,8,9,11,12,18$ and 20 with resistance to $\mathrm{SCN}$ races 2 and 3 , race 3 , races 1 and 3 , race 1 , races 1,3 and 5 , race 1 , races $1,2,3$ and 5 , and races 3,5 and 14, respectively (Wu et al. 2009).

In China, Chang et al. (2011) mapped seven QTL, Qscn3-1 on chromosome 15, Qscn3-2 on chromosome 18, Qscn3-3 on chromosome 16, Qscn14-1 on chromosome 10, Qscn14-2 on chromosome 10, Qscn14-3 on chromosome 17, and Qscn14-4 on chromosome 16, in a Chinese resistant soybean source 'L-10', with the first three conferring resistance to $\mathrm{SCN}$ race 3 , and the last four conferring resistance to $\mathrm{SCN}$ race 4 . Through genotyping by specific locus amplified fragment sequencing (SLAF-seq) and genome-wide association study (GWAS) analyses, 19 QTLs including three new QTLs were identified in 131 novel soybean sources conferring resistance to SCN race 3, 4 or both (Han et al. 2015). Furthermore, Yang et al. (2021) mapped the qSCN3-1 on chromosome 01 in the Chinese soybean line 'Zhongpin 035373' with resistance to SCN race 3.

Due to the importance of $r h g 1$ in the resistance of soybean to $\mathrm{SCN}$, fine mapping of this locus was performed. Ruben et al. (2006) analyzed the recombination events at rhg1- $a$ using nine DNA markers, performed the genomic analyses of rhg1-a, constructed the physical map of rhg1- $a$ using Forrest BAC library, and eventually cloned a leucine-rich repeat-receptor like kinase (LRR-RLK) gene, which was tightly linked with the two neighboring genes: a laccase gene and a hydrogen sodium ion antiporter gene (Afzal et al. 2012). Kim et al. (2010) narrowed the resistance of $r h g 1$ to a genomic region of 67 $\mathrm{kb}$ containing 11 genes by screening the recombinants using four different recombinant inbred lines (RILs) populations, laying a basis for the functional identification of the rhg1-b gene (Cook et al. 2012).

\section{SCN-resistant genes identified in soybean}

The rhg1 on chromosome 18 and the Rhg4 on chromosome 08 are the two major QTL underlying the resistance to SCN in soybean (Meksem et al. 2001; Concibido 
et al. 2004). The rhg1 contains two types: Peking-type rhg1- $a$ and PI 88788-type rhg1-b (Brucker et al. 2005; Kim et al. 2010). The Peking-type soybeans require both rhg1- $a$ and Rhg4 for the SCN resistance, while only rhg1- $b$ is sufficient for the SCN resistance in PI 88788type soybeans (Meksem et al. 2001; Brucker et al. 2005). Two $L R R-R L K$ genes within these two QTL had been considered as the SCN-resistant genes until two reports provided functional validation that neither of these two LRR-RLKS conferred the SCN resistance (Melito et al. 2010; Liu et al., 2011b). From a 67-kb resistant rhg1 candidate genomic region (Kim et al. 2010), Cook et al. (2012) identified multiple tandem copies of a genomic segment of about $31 \mathrm{~kb}$ in the SCN-resistant soybeans (three copies in Peking-type soybeans, and 10 copies in PI 88788-type soybeans), while only one copy of this segment in the susceptible soybeans such as Williams 82. This multiple tandem genomic segment contains four whole genes and a partial gene, of which, three genes (Glyma.18 g022400 (GmAAT, an amino acid transporter), Glyma.18 g022500 (GmSNAP18, an $\alpha$-SNAP, $\alpha-$ soluble N-ethylmaleimide sensitive factor (NSF) attachment protein) and Glyma.18g022700 (GmWI12, a wound-induced protein)) were demonstrated to simultaneously contribute to the SCN resistance in PI 88788type soybeans (Cook et al. 2012). As such, the SCN resistance of $r h g 1-b$ is accomplished by multiple copies of three tandem genes, which was verified by follow-up reports (Cook et al. 2014; Lee et al. 2015; Yu et al. 2016). Meanwhile, the sole GmSNAP18 in a Peking-derived soybean cultivar 'Forrest', showing five-nucleotide polymorphisms resulting in five-amino acid residue alterations as compared with rhg1-b GmSNAP18, was cloned by high density genetic mapping and RSE-seq (RegionSpecific Extraction Sequencing) and functionally identified as the rhg1-a gene (Liu et al. 2017). The GmSHMT08 (Glyma.08 g108900, a serine hydroxymethyltransferase) on chromosome 08 was cloned from the resistant Forrest and functionally validated as the Rhg4 gene (Liu et al. 2012). The rhg1-a GmSNAP18 together with Rhg4 GmSHMT08 mediate the SCN resistance of Peking-type soybeans against SCN (Liu et al. 2012, 2017; Kandoth et al. 2017). In addition, the GmSNAP11 (Glyma.11 g234500, another $\alpha$-SNAP) on chromosome 11 was identified as a minor gene contributing to the resistance of soybean to SCN (Matsye et al. 2012; Lakhssassi et al. 2017).

On the other hand, some other candidate genes were identified as likely contributors to the SCN resistance in soybean. These candidate genes include Glyma.10 g194800, Glyma.10g195600, Glyma.10g195700 and Glyma.10g196700 in qSCN10, encoding a bZIP transcription factor, an SNF7 family protein, a receptor-like kinase and a CC-NBS-LRR protein, respectively (Vuong et al. 2010; Kadam et al. 2016; Zhou et al. 2021); the transcription factor Glyma.11 $\mathrm{g} 230200$ in qSCN11 (Kadam et al. 2016); and Glyma.18g244200 and Glyma.18 g244600 encoding a mitogen-activated protein kinase and an AP2 domain transcription factor, respectively, in qSCN18 (Usovsky et al. 2021).

In China, Liu et al. (2019) reported that three candidate genes, Glyma.09g054000, Glyma.16g065700 and Glyma.18 g192200, likely conferred resistance to SCN race 4 by comparative genomic analyses of two segregating PI 437654 mutants generated via EMS mutagenesis. (Ge et al. 2018). Yang et al. (2021) proposed two candidate genes, Glyma.01 g057100 and Glyma.01 g058000, at the qSCN3-1 locus, both of which were highly expressed in the soybean roots, and an amino acid alteration was shown at Glyma.01 g057100, while no amino acid changes were detected at Glyma.01 g058000 between resistant $c v$. Zhongpin03-5373 and susceptible $c v$. 'Zhonghuang 13 '.

\section{Specific molecular makers and high-throughput identification of soybean resistance against SCN}

Previously, the SSR (simple sequence repeat) makers were usually employed for the marker-assisted selection of soybean resistance against SCN, such as Satt309 in rhg1 and Sat_162 in Rhg4 (http://www.soybase.org). Nan et al. (2009) developed an InDel (insertion and deletion) marker, rhg1-I4, in rhg1, and using this marker, 88.2 and $100 \%$ of the resistant and susceptible lines, respectively, were correctly evaluated from a panel containing 33 soybean lines. Combining rhg1-I4 with another developed marker, SCN_Res Bridge, the correct evaluation matching genotypes with phenotypes of resistant lines reached $88.89 \%$ in $265 \mathrm{~F}_{2: 3}$ plants from a cross between Huipizhiheidou and 'Heilong 33' (Ma et al. 2014). Shi et al. (2015a) developed a CAPS marker (Rhg4-389) and a dCAPS marker (Rhg4-1165), both of which were associated with Rhg4 gene GmSHMT08. Tian et al. (2019) developed a CAPS marker, GmSNAP11-2565, associated with the minor SCN-resistant gene GmSNAP11, and evaluated the SCN resistance of a soybean panel containing 209 lines by combining the GmSNAP11-2565 marker with the Rhg4-389 CAPS marker and the rhg12 KASP marker located in the 6th exon of GmSNAP18. Recently, Yang et al. (2021) developed 47 more new InDel markers, and combining rhg1-2 KASP, Rhg4-389 CAPS marker and GmSNAP11-2565 with the two developed markers (Map-0047_CAPS in the 7th exon of Glyma.01 g059200 and InDel1-7 in the upstream region of Glyma.01 g0540500 and Glyma.01 g054600 in qSNC3-1) resulted in an increase in the correct evaluations of resistance against $\mathrm{SCN}$ race 3.

To efficiently identify resistance sources and improve the efficiency and cost-effectiveness of molecular 
breeding, it is necessary to develop more accurate molecular markers and high-throughput selection methods. On the basis of the genomic sequences of identified $r h g 1$ and Rhg4 genes (Cook et al. 2012; Liu et al. 2012), Shi et al. (2015b) developed three specific SNP markers, GSM191 in the 1st exon of GmSHMT08, GSM381 in the 9th exon and GSM383 in the 6th exon of GmSNAP18, for KASP (Kompetitive Allele Specific PCR) assay, following comparisons of the genomic sequences of four genes, Glyma.18 g022400, GmSNAP18 and Glyma.18g022700 on rhg1, and GmSHMT08 on Rhg4, in 27 representative soybean lines including germplasm sources and varieties. Using KASP assays, these three developed markers were validated on a panel of 153 soybean lines, showing around $93 \%$ of correlation between the SNP genotypes and SCN race 3-infection phenotypes, and also on a F5-derived RILs population from G00-3213 × LG04-6000 which also showed a strong genotype-phenotype correlation. Subsequently, Kadam et al. (2016) used 19,652 publicly available accessions genotyped with SoySNAP50K iSelect BeadChip to perform the phylogenetic analyses and developed several rhg1and Rhg4-specific SNP markers to differentiate the copy number variation $(\mathrm{CNV})$ of rhg1 and different types of Rhg4 for a high-throughput KASP assay. KASP technology was also used to identify the SCN resistance of 202 soybean lines, collected from eight countries with known resistance/susceptibility to SCN race 3, with a developed SNP maker (GmSNAP11-5149 at the SCN3-11 locus on chromosome 11), resulting in $92 \%$ accuracy (Tian et al. 2018). As a result, high-throughput SCN resistance identification of soybean can be efficiently realized using the robust and specific SNP markers by KASP assay.

\section{Resistance mechanisms of soybean against SCN}

The resistance mechanisms of soybean to SCN remain only partially known. So far, the resistance mechanism of soybean against SCN conferred by multiple copies of resistant genes has been clarified. A genomic fragment of $31 \mathrm{~kb}$ containing four entire genes and one partial gene, including GmAAT, GmSNAP18 and GmWI12, in rhg1 on chromosome 18 presented low copies (2-4) in Peking-type soybeans, high copies $(>6,7-10)$ in PI 88788-type soybeans, but only one copy in susceptible soybeans, and these three random genes simultaneously mediated the resistance of rhg1- $b$ through a high copy number (Cook et al. 2012, 2014; Lee et al. 2015, Yu et al. 2016). The presence of more copies of Rhg4 GmSHMT08 was required to confer resistance to multiple SCN races (Patil et al. 2019). Further, a Peking-type Rhg4 GmSHMT08 haplotype was required for SCN resistance when the copy numbers of GmSNAP18 were below 5-6. In contrast, the SCN resistance of soybean requiring at least 5-6 copies of PI 88788 rhg1- $b$ was unrelated to the genotype of Rhg4 GmSHMT08 (Patil et al. 2019).

It is known that GmSNAP18 plays an important role in SCN resistance conferred by rhg1. During infection of soybean plants by SCN, a large quantity of abnormal GmSNAP18 was accumulated at the SCN feeding sites, which showed cytotoxicity and disrupted SNARE complexes and vesicle trafficking, likely causing the resistance of soybean to SCN (Bayless et al. 2016). The GmSNAP18-mediated SCN resistance occurred via its interaction with other proteins in soybean. The $\mathrm{NSF}_{\text {RAN07 }}$ (Glyma.07 g195900) could strongly bind with the resistant rhg1 SNAPs, protecting it from the cytotoxicity caused by GmSNAP18 and imparting the sustainability of SCN resistance of rhg1 (Bayless et al. 2018). The GmSNAP18 was targeted by $2 \mathrm{t}$-SNARE domaincontaining syntaxins (Glyma.12 g194800 and Glyma.16 g154200) for mediation of the SCN resistance in soybean (Dong et al. 2020). The rhg1-a GmSNAP18 could crosstalk with Rhg4 GmSHMT08, with the involvement of a soybean pathogenesis-related protein GmPR08-Bet VI, to stimulate the resistance of Peking-type soybeans against SCN (Lakhssassi et al. 2020). In addition, the differentially methylated DNA regions within rhg1 correlated with the resistance of soybean to SCN (Cook et al. 2014).

The Rhg4 GmSHMT08 (Liu et al. 2012) is an enzyme in the one-carbon metabolism pathway, converting serine to glycine with the supply of a one-carbon unit. Enzyme kinetic analysis showed a significant difference between resistant Forrest- and susceptible EssexGmSHMT08 (Liu et al. 2012). The two polymorphic amino acid residues (P130R and N358Y) in GmSHMT08 could influence the mobility of a loop close to the entrance of the binding site of (6S)-tetrahydrofolate (THF), fairly decreasing the affinity to the substrates, and as a result, the enzymatic activity of resistant GmSHMT08 was significantly reduced, showing resistance against SCN (Karosick et al. 2020). All these results point to the likely involvement of one-carbon metabolism in the Rhg4-mediated SCN resistance mechanism.

During the incompatible interaction of soybean with $\mathrm{SCN}$, the resistant soybeans display two types of responses to counteract the attack of SCN: rapid and strong responses by Peking-type soybeans, in which the nematodes usually stop developing at the J2 stage; whereas in the slow but sustainable responses by PI 88788-type soybeans, generally, the nematodes are able to develop until J3 or J4 stage (Klink et al. 2007a, 2007b, 2009). These defense responses have been widely analyzed at different levels (transcriptome and proteome). Using Affymetrix Soybean GeneChip, the mircoarray analyses of the syncytium cells isolated by a laser capture microdissection (LCM) method identified 1447 
differentially expressed genes (DEGs) between 2 near isogenic lines (NILs) of rhg1, susceptible NIL-S and resistant NIL-R, of which 241 genes were up-regulated, including GmAAT and GmSNAP18, and these genes were associated with stress tolerance and disease defense (Kandoth et al. 2011). Another microarray study also indicated that both GmAAT and GmSANP18 were specifically expressed in defense responses of soybeans Peking and PI 88788 to infection by SCN (Matsye et al. 2011). The functions of some genes selected from the transcriptome analyses were verified by genetic transformation. Overexpression or VIGS of the genes encoding many factors, such as superoxide dismutase, chalcone synthase, heat shock proteins, ascorbate peroxidase, $ß$ 1,4-glucanase, short chain dehydrogenase, lipase, DREPP membrane protein, calmidulin, syntaxin 31 and CLE receptors, could alter the resistance of soybeans to SCN (Matthews et al. 2013; Pant et al. 2014, 2015; Woo et al. 2014; Guo et al. 2015). Through comparative analyses of the proteins and metabolic pathways in two soybean NILs, resistant NIL34-23 and susceptible NIL-3, with and without infection by SCN, 28 differentially expressed proteins were identified, and 17 metabolic pathways associated with systematic acquired resistance were altered at the rhg1 locus between these two NILs due to the infection with SCN (Afzal et al. 2009). Recently, the conserved oligomeric Golji (COG) complex (Lawaju et al. 2020) and a plasma membrane protein GmDR1 (Ngaki et al. 2021) were also found to be involved in the defense response of soybean against $\mathrm{SCN}$.

As reported, overexpression of a soybean salicylic acid methyltransefase gene, GmSAMT1, which is involved in the salicylic acid (SA) signaling pathway in SCNsusceptible soybean lines, conferred resistance to SCN (Lin et al. 2013). Transformation of the Arabidopsis genes associated with SA-mediated signaling pathway, such as AtPAD4, AtNPR1, AtTAG2 and AtPR-5, into susceptible soybean lines could also increase the resistance against SCN (Youssef et al. 2013; Matthews et al. 2014). Overexpression of GmWRKYs, soybean WRKYtype transcription factor genes responsive to SA, could improve soybean resistance to SCN (Yang et al. 2017). Recently, Jiang et al. (2020) reported that GmWRKYX1 was expressed over 60 -fold more at $10 \mathrm{dpi}$ than at $0 \mathrm{dpi}$ after inoculation of soybean with $\mathrm{SCN}$ race 3. Further, overexpression of GmAAT, a gene at the rhg1 locus, could activate jasmonic acid (JA) signaling pathway, and treatment with a JA biosynthesis inhibitor, n-propyl gallate $(\mathrm{nPG})$ at $100 \mu \mathrm{M}$, could significantly reduce the resistance of PI 88788 to SCN (Guo et al. 2019). All these suggest the involvement of SA and JA signaling pathways in the resistance of soybean against SCN.

DNA methylation also impacts the resistance of soybean to SCN. Rambani et al. (2015) identified 278 specifically methylated genes, which are associated with epigenetic regulation, phytohormone signal transduction, cell wall structure, signaling transduction and ubiquitination, from the syncytium of Williams 82 infected by $\mathrm{SCN}$. After infection with SCN, the global methylation levels of many protein-coding genes and transposable elements would be suppressed in susceptible soybeans, whereas they were promoted in resistant soybeans, and the DNA methylation levels associated with incompatible (resistant) and compatible (susceptible) interactions of soybean with SCN were highly specific (Rambani et al. 2020).

\section{Integrated management of SCN}

In China, each small soybean farmer cultivates soybean on an average area of approximately 2 ha. There are also large state farms and farmers' cooperatives, which cultivate soybean on large areas of land (approximately 200 ha of land for each large farm). Due to differences in their ability to purchase inputs such as resistant cultivars and nematicides, the implementation level of integrated nematode management (INM) of soybean is therefore very different between small and large farms. SCN management by small farmers is mainly dependent on crop rotation with non-host crops and planting resistant cultivars, while rotation, planting resistant cultivars and some chemical control with seed-coating treatments are normally used for INM by state farms and large farmers' cooperatives.

There is a good agricultural extension system in China, consisting of a National Agricultural Technology Extension and Service Center as the central administration, a general Plant Protection Station (PPS) in each province, and a local PPS in each county. Therefore, a complete agricultural technology extension service network has been established, and the extension will be further developed to cover all small farmers and farmers' cooperatives, so that they could acquire real-time information on SCN occurrence.

SCN management mainly depends on planting resistant varieties, crop rotation with non-host crops, applying nematicides, cover cropping and biological control. In China, cover cropping is seldom adopted for the SCN management.

\section{Host plant resistance}

Currently, planting SCN-resistant cultivars is the primary means for nematode control. SCN-resistant cultivars can invoke defense against SCN populations, and a solid understanding of SCN genome information is the basis for analyzing the pathogenicity mechanisms and breeding of new SCN-resistant cultivars (Lian et al. 2019). In China, major efforts have been made to develop soybean cultivars with resistance to SCN HG Type 
1.2.3- (race 4) in Huanghuaihai Valley and to SCN HG Type 0 (race 3) in Northeast China (Lian et al. 2017). Three soybean cultivars, 'Zhonghuang 12', 'Zhonghuang 13 ' and 'Zhonghuang 17' with moderate resistance to SCN race 4, were released in Beijing, Anhui Province, Tianjin and North China (Wang et al. 2002). By crossing Hartwig with Jin 1265, and evaluation of SCN resistance in their offspring, seven yellow varieties ('ZP03-5334', 'ZP03-5355', 'ZP03-5363', 'ZP03-5364', 'ZP03-5366', 'ZP03-5368', and 'ZP03-5373') were selected, all of which possessed good agronomic and economic traits, as well as high resistance to SCN race 4 (Liu et al. 2008).

A series of varieties ('Kangxian 1, 2, 3, 4, 5, 6, 7, 8, 9, 10, 11, 12 and 13') conferring resistance to HG Type 0 (race 3) were developed by Heilongjiang Academy of Agricultural Sciences in Northeast China (Tian et al. 2007; Yu et al. 2013). 'Kangxian 1' was awarded the 4th National Invention Prize in 1997 (Duan et al. 2014). To date, more than 30 varieties including the 'Kangxian series' varieties with high yield and SCN resistance were commercially released in China from 1988 to 2020. Those varieties include 'Lengfeng 14', 'Lengfeng 15', 'Lengfeng 18', 'Lengfeng 19', 'Lengfeng 20', 'Qingfeng 1', 'Fengdou 3', 'Qinong 1', 'Qinong 2', 'Qinong 5', 'Shundou 1', 'Pengdou 1', 'Fudou 6', 'Nongqingdou 20', 'Nongqingdou 24', 'Andou 162' and 'Heinong 531' (personal communication, unpublished).

\section{Crop rotation}

Crop rotation is an effective means for SCN management. Rotations of soybean with non-host gramineous crops, such as wheat, corn and millet, can effectively control SCN. Normally, 2 years of rotation with nonhost plants would allow planting of susceptible soybean varieties in the next season (Peng et al. 1999).

\section{Chemical control}

It is suggested to treat soil and coat seeds with nematicides in fields that have been seriously infested with $\mathrm{SCN}$. However, the nematicides are expensive, and a high dosage is usually needed, which leads to serious pollution and, as a result, this method cannot be used regularly. At present, the effective nematicides include 10\% Fosthiazate GR, 0.5\% Avemactin, 70\% imidacloprid and carbofuran (Luo et al. 2020).

\section{Biological seed-coating agents}

In the late 1990s, the biocontrol granule-formulated 'Doufeng 1' made from Pochonia chlamydosporium was developed for the prevention and control of SCN. This granule used organic manure as a carrier for fixing the biocontrol agent ( $P$. chlamydosporium) and trace elements. The biocontrol agents can easily survive and reproduce in soil, and then develop into a dominant population to continuously suppress the development of nematode populations (Chen et al. 2011). Recently, several biological seed-coating agents were developed and applied to control SCN in soybean field. The crushed castor seed shell showed a good effect on controlling SCN, which could not only inhibit cyst nematode parasitism of soybean roots but also increase soybean yield (Liu et al. 2014). The new types of 'Junxianke' series biological seed-coating formulations ('SN100', 'SN101' and 'SN102'), with biological fermentation products as the main components, can also be used to control SCN. All these three formulations displayed good effects on SCN control, of which SN101 exhibited the highest control effect on SCN (up to $74.52 \%$ ), while SN102 showed the best effect on yield increase (Yuan et al. 2020). 'Helisu' (brassinosteroids plus Bacillus amyloliquefaciens) could efficiently suppress SCN and decrease the formation of cysts in soybean roots. In addition, Helisu treatment at the early growth stage could also stimulate the growth and development of soybean plants (Wang et al. 2017). $\mathrm{Du}$ et al. (2009) developed a biological seed-coating agent ('HND1') from Verticillium chlamydiae, which showed good efficiency in controlling SCN. Cheng et al. (2008) found that seed coating with Bacillus thuringiensis could control SCN in soybean field, and the control efficiency was significantly better than that of the normal nematicide treatments when dressing soybean seeds at a ratio of 1:60 (bacterial suspension: seed). Compared to the conventional chemical pesticide treatments, the SCN control efficiency was better, and the soybean yield was significantly increased when dressing soybean seeds with $4000 \mathrm{IU} / \mu \mathrm{L}$ of $B$. thuringiensis suspension (Liu et al. 2011a).

\section{Outlook-future directions}

China is the largest soybean consumer and importer in the world. The domestic soybean production of China is unable to meet its consumption demands. In China, the total soybean production in 2019 was only 18.1 million tons, and 88.51 million tons of soybean was imported, that is, more than $80 \%$ of soybean consumption relied heavily on import from the USA, Brazil and Argentina. The total soybean imports are expected to exceed 100 million tons in China in 2020.

Soybean is not only a source of high-quality vegetable protein, but also a source of healthy edible vegetable oil. With the upgrading of residents' consumption structure, the demand for soybean is increasing rapidly, and the gap between domestic production and demand is expanding. Under the new situation, it is necessary to actively respond to the complicated international trade environment, promote the recovery and development of China's soybean production, improve soybean selfsufficiency, and reduce the dependence on imported 
soybean, to ensure the implementation of the national food security strategy. According to the 'Soybean Revitalization Plan' issued by Chinese government, the soybean planting area is estimated to reach 11 million ha by 2050 in China, and the number of small farmers will be reduced, whereas the number of large farms will be increased. Further, the land transfer will produce many new soybean production cooperatives or farms. Along with climate change and agricultural industrial structure adjustment, $H$. sojae will spread to the northern soybean growing area, which will potentially threaten the soybean production. New nematicides (fluopyram, fluensulfone) and biological seed-coatings are needed for seed treatments in the future.

Although several SCN-resistant genes have been cloned, such as rhg1-b GmAAT, GmSNAP18 and GmWI12 (Cook et al. 2012), Rhg4-GmSHMT08 (Liu et al. 2017), rhg1-a GmSNAP18 (Liu et al. 2017) and GmSNAP11 (Lakhssassi et al. 2017), the identified SCNresistant genes are still very limited, and the corresponding resistance mechanisms conferred by these genes remain unclear. Moreover, the resistance will be overcome with the emergence of new virulent races of SCN (Kandoth et al. 2017). Therefore, it is necessary to identify more new SCN-resistant genes, breed novel resistant varieties to support soybean production, and meanwhile strengthen the study on SCN resistance mechanisms in soybean.

With the rapid development of modern biotechnology and wide application of next-generation sequencing and metagenomics technology, QTL mapping, cloning nematode-resistant genes and mining new resistance resources are greatly promoted. CRISPR/Cas-based systems provide powerful gene editing tools to manipulate genomes of almost all species including nematodes, and stimulate research on functional identification of candidate genes and crop breeding. An efficient CRISPR/Cas9 gene-editing platform driven under AtEC1.2e1.1p in soybean and Arabidopsis was developed by Zheng et al. (2020), which resolved the non-inheritable and unstable problem occurring in somatic transformation. It provides an easy-to-use way to study SCN-resistant candidate genes, and can also be used to generate cultivars that are resistant against SCN in the future. CRISPR/Cas genome editing technology has brought about a revolution in life sciences, which will undoubtedly accelerate the functional identification of nematode-resistant genes and also the underlying resistance mechanisms.

In the infection process, $\mathrm{SCN}$ secretes effectors into host cells to induce the formation of feeding sites (syncytia) and meanwhile complete its life cycle. Many effectors have been predicted and identified from SCN to show either virulence or avirulence (Gao et al. 2003; Bakhetia et al. 2007; Peng et al. 2012a, b, Peng et al. 2016a, b, Gardner et al. 2018; Zhang et al. 2018; $\mathrm{Hu}$ et al. 2019; Masonbrink et al. 2019; Wang et al. 2019). However, there are few reports on how these effectors directly interact with the identified SCN-resistant proteins. Bekal et al. (2015) predicted two effector genes, $\mathrm{HgBioB}$ and a t-SNARE domain-containing protein gene HgSLP-1, by genomic analyses, and found HgSLP-1 could interact with GmSNAP18, but neither has yet been functionally characterized thus far. It is promising to understand the resistance mechanism of soybean against SCN via investigating the effectors that directly interact with resistant host proteins.

In 2019, China launched its national 'Soybean Revitalization Plan', and the Ministry of Agriculture and Rural of China released the detailed implementation scheme for this plan on March 15, 2019. In 2020, the total national soybean planting area reached 9.33 million ha, and the national average soybean yield was 2 tons per ha. With the expansion of the Northern soybean growing area, the occurrence, damage and population dynamics of SCN will present some new characteristics, and therefore, new measures should be adopted to improve the integrated nematode management level in China, for example, the remote sensing technology will be widely used to monitor the occurrence and damage of SCN in the near future.

By using modern breeding technologies, the existing germplasm resources have been comprehensively utilized and new germplasm sources are being created to accelerate the breeding of early maturing and resistant soybean varieties. Further increases in resistance breeding are still needed to release more resistant cultivars into the market.

Seed-coating technology shows a promising application prospect in managing $\mathrm{SCN}$, and is a feasible direction method for controlling SCN in the future. Presently, developing new biological control products and seed-coating technologies are still necessary for long-term management of SCN.

Additionally, we must achieve crop rotation optimization. To prevent the emergence and spread of new virulent races that can overcome the resistance of existing soybean cultivars, rotation with either non-host plants or susceptible soybean varieties should be considered.

\section{Conclusions}

The plant parasitic nematode $\mathrm{SCN}$ is a destructive threat to global soybean production, causing devastating yield losses annually. So far, 11 SCN races, including a newly identified super-virulent race X12, have been identified in 22 provinces, causing over 120 million dollars of annual yield loss in China. As has been mentioned above, great progress has been achieved in SCN research, 
including the occurrence, distribution, races, molecular diagnosis, genome and effectors of SCN; identification of soybean germplasm resources resistant to SCN, QTL mapping in soybean underlying the $\mathrm{SCN}$ resistance, high-throughput resistance identification, identification of SCN-resistant genes and the underlying resistance mechanism; and also measures for integrated management of SCN including biological control. However, to reduce soybean production losses caused by $\mathrm{SCN}$, it still needs further study on both the virulence mechanism of SCN and the resistance mechanism of soybean, identification of new SCN-resistant germplasm resources and novel SCN-resistant genes, breeding of new resistant cultivars and improvement of integrated SCN management level.

\section{Abbreviations}

CGE: Coordinative group of evaluation; DEG: Differentially expressed gene; J2: Second juvenile; J3: Third juvenile; J4: Forth juvenile; JA: Jasmonic acid; KASP: Kompetitive allele specific PCR; LRR-RLK: Leucine rich repeat-receptor like kinase; NIL: Near isogenic line; NSF: N-ethylmaleimide sensitive factor; QTL: Quantitative trait locus; RIL: Recombinant inbred line; RPA: Recombinase polymerase amplification; RSE-Seq: Region specific extraction-sequencing; SA: Salicylic acid; SCN: Soybean cyst nematode; SHMT: Serine hydroxymethyltransferase; SLAF-Seq: Specific locus amplified fragmentsequencing; SNAP: Soluble NSF attachment protein; SNP: Single nucleotide polymorphism; TILLING: Targeting induced local lesions in genomes

\section{Acknowledgements}

We thank all the members of the Crop Nematode Diseases Laboratory at the Institute of Plant Protection, Chinese Academy of Agricultural Sciences, China, for their contributions in SCN and soybean resistance researches, which are included in this manuscript.

\section{Authors' contributions}

DP and SL wrote and revised the manuscript. RJ and HP helped collect the relevant references and assisted in writing. All authors read and approved the final manuscript.

\section{Funding}

This work was financially supported by the National Natural Science Foundation of China $(31972248,31772142)$ and the Special Fund for AgroScientific Research in the Public Interest of China (210503114).

\section{Availability of data and materials}

Not applicable.

\section{Declarations}

Ethics approval and consent to participate

Not applicable.

\section{Consent for publication}

Not applicable.

\section{Competing interests}

The authors declare that they have no competing interests.

Received: 18 February 2021 Accepted: 15 July 2021

Published online: 08 August 2021

\section{References}

Afzal AJ, Natarajan A, Saini N, labal MJ, Geisler M, El-Shemy HA, et al. The nematode resistance allele at the rhal locus alters the proteome and primary metabolism of soybean roots. Plant Physiol. 2009;151:1264-80.

Afzal AJ, Srour A, Saini N, Hemmati N, El Shemy HA, Lightfoot DA. Recombination suppression at the dominant Rhg1/Rfs2 locus underlying soybean resistance to the cyst nematode. Theor Appl Genet. 2012;124(6):1027-39. https://doi. org/10.1007/s00122-011-1766-6.

Anand SC. Registration of 'Hartwig' soybean. Crop Sci. 1992;32:1069-70.

Arelli PR, Mengistu A, Nelson RL, Cianzio SR, Vuong T. New soybean accessions evaluated for reaction to Heterodera glycines populations. Crop Sci. 2015;55: $1236-42$.

Atibalentja N, Bekal S, Domier LL, Niblack TL, Noel GR, Lambert KN. A genetic linkage map of the soybean cyst nematode Heterodera glycines. Mol Gen Genomics. 2005;273:273-81

Bakhetia M, Urwin PE, Atkinson HJ. qPCR analysis and RNAi define pharyngeal gland cell expressed genes of Heterodera glycines required for initial interactions with the host. Mol Plant-Microbe Interact. 2007;20(3):306-12. https://doi.org/10.1094/MPMI-20-3-0306.

Bao Y, Vuong T, Meinhardt C, Tiffin P, Denny R, Chen S, et al. Potential of association mapping and genomic selection to explore $\mathrm{Pl} 88788$ derived soybean cyst nematode resistance. Plant Genome. 2014;7:1-13.

Bayless AM, Smith JM, Song J, McMinn PH, Teillet A, August BK, et al. Disease resistance through impairment of a-SNAP-NSF interaction and vesicular trafficking by soybean Rhg1. Proc Natl Acad Sci U S A. 2016;113:E7375-82.

Bayless AM, Zapotocny RW, Grunwald DJ, Amundson KK, Diers BW, Bent AF. An atypical $\mathrm{N}$-ethylmaleimide sensitive factor enables the viability of nematoderesistant Rhg1 soybeans. Proc Natl Acad Sci U S A. 2018;115(19):E4512-21. https://doi.org/10.1073/pnas.1717070115.

Bekal S, Domier LL, Gonfa B, Lakhssassi N, Meksem K, Lambert KN. A SNARE-like protein and biotin are implicated in soybean cyst nematode virulence. PLoS One. 2015;10(12):e0145601. https://doi.org/10.1371/journal.pone.0145601.

Brucker E, Carlson S, Wright E, Niblack T, Diers B. Rhg1 alleles from soybean PI 437654 and PI 88788 respond differentially to isolates of Heterodera glycines in the greenhouse. Theor Appl Genet. 2005;111:44-9.

Chang W, Dong L, Wang Z, Hu H, Han Y, Teng W, et al. QTL underlying resistance to two HG types of Heterodera glycines found in soybean cultivar 'L-10'. BMC Genomics. 2011;12:233.

Chen LJ, Wang YY, Zhu XF, Duan YX. Review of the biocontrol on soybean cyst nematode (Heterodera glycines). J Shenyang Agric Univ. 2011;42(4):393-8 (in Chinese). http://en.cnki.com.cn/Article_en/CJFDTOTAL-SYNY201104004.htm.

Chen PS, Zhang DS, Chen SY. First report on a new physiological race (race 7) of soybean cyst nematode (Heterodera glycines). Sci Agric Sin. 1987;20(2):94-5 (in Chinese).

Cheng YC, Bai QJ, Chen SK, Lu RL, Wang XL. Application the seed coating of Bacillus thurringensis suspension to control soybean cyst nematode at soybean field experiments. Inner Mongolia Agric Sci Technol. 2008;6:52 (in (hinese).

Chitwood DJ. Research on plant-parasitic nematode biology conducted by the United States Department of Agriculture-Agricultural Research Service. Pest Manag Sci. 2003;59(6-7):748-53. https://doi.org/10.1002/ps.684.

Colgrove AL, Niblack TL. Correlation of female indices from virulence assays on inbred lines and field populations of Heterodera glycines. J Nematol. 2008;40: $39-45$

Concibido VC, Denny RL, Boutin SR, Hautea R, Orf JH, Young ND. DNA marker analysis of loci underlying resistance to soybean cyst nematode (Heterodera glycines Ichinohe). Crop Sci. 1994;34:240-6.

Concibido VC, Denny RL, Lange DA, Orf JH, Young ND. RFLP mapping and marker-assisted selection of soybean cyst nematode resistance in PI 209332. Crop Sci. 1996;36:1643-50.

Concibido VC, Diers BW, Arelli PR. A decade of QTL mapping for cyst nematode resistance in soybean. Crop Sci. 2004;44:1121-31.

Concibido VC, Lange DA, Denny RL, Orf JH, Young ND. Genome mapping of soybean cyst nematode resistance genes in 'Peking', PI 90763, and PI 88788 using DNA markers. Crop Sci. 1997;37:258-64.

Cook DE, Bayless AM, Wang K, Guo X, Song Q, Jiang J, et al. Distinct copy number, coding sequence, and locus methylation patterns underlie Rhg 1-mediated soybean resistance to soybean cyst nematode. Plant Physiol. 2014;165:630-47.

Cook DE, Lee TG, Guo X, Melito S, Wang K, Bayless AM, et al. Copy number variation of multiple genes at Rhgl mediates nematode resistance in soybean. Science. 2012;338:1206-9.

Coordinative Group of Evaluation of SCN. Evaluation of soybean germplasm for resistance to race 1, 3 and 4 of the soybean cyst nematode. Soybean Sci. 1993;12(2):91-9 (in Chinese). http://ddkx.haasep.cn/oa/DArticle.aspx?type= view\&id=199302001.

Cui YH, Qiu $\sqcup$, Chang RZ, Lu WH. Advances in research on core collection of plant germplasm resources. J Plant Genet Res. 2003;4:279-84 (in Chinese). 
de Boer JM, Overmars HA, Pomp H, Davis EL, Zilverentant JF, Goverse A, et al. Production and characterization of monoclonal antibodies to antigens from second stage juveniles of the potato cyst nematode, Globodera rostochiensis. Fundam Appl Nematol. 1996;19:545-54.

Dong J, Zielinski RE, Hudson ME. T-SNAREs bind the Rhg 1-SNAP and mediate soybean cyst nematode resistance. Plant J. 2020;104:318-31.

Du CM, Li HY, LI XM, Wang YJ, Liu TR, Ping WX. Control effects of HND1 biological seed coating on soybean cyst nematode. Soybean Sci. 2009;28(6): 1126-9 (in Chinese).

Duan YX, Peng DL. Soybean Cyst Nematode. In: Institute of Plant Protection, Chinese Academy of Agricultural Sciences, Chinese Society of Plant Protection, editor. Plant Disease and Pests on China Agricultural Crops (3rd ed). Beijing: China Agriculture Press; 2014. p. 1039-46. (in Chinese).

Gao B, Allen R, Maier T, Davis EL, Baum TJ, Hussey RS. The parasitome of the phytonematode Heterodera glycines. Mol Plant-Microbe Interact. 2003;16:7206.

Gardner M, Dhroso A, Johnson N, Davis EL, Baum TJ, Korkin D, et al. Novel global effector mining from the transcriptome of early life stages of the soybean cyst nematode Heterodera glycines. Sci Rep. 2018;8:2505.

Ge FY, Zheng N, Zhang LP, Huang WK, Peng DL, Liu SM. Chemical mutagenesis and soybean mutants potential for identification of novel genes conferring resistance to soybean cyst nematode. J Integr Agric. 2018;17:2734-44.

Glover KD, Wang D, Arelli PR, Carlson SR, Cianzio SR, Diers BW. Near isogenic lines confirm a soybean cyst nematode resistance gene from PI 88788 on linkage group. J Crop Sci. 2004;44:936-41.

Guo B, Sleper DA, Arelli PR, Shannon JG, Nguyen HT. Identification of QTLS associated with resistance to soybean cyst nematode races 2, 3 and 5 in soybean PI 90763. Theor Appl Genet. 2005;111:965-71.

Guo B, Sleper DA, Nguyen HT, Arelli PR, Shannon JG. Quantitative trait loci underlying resistance to three soybean cyst nematode populations in soybean PI 404198A. Crop Sci. 2006;46:224-33.

Guo W, Zhang F, Bao A, You Q, Li Z, Chen J, et al. The soybean Rhgl amino acid transporter gene alters glutamate homeostasis and jasmonic acid-induced resistance to soybean cyst nematode. Mol Plant Pathol. 2019;20:270-86.

Guo X, Chronis D, De La Torre CM, Smeda J, Wang X, Mitchum MG. Enhanced resistance to soybean cyst nematode Heterodera glycines in transgenic soybean by silencing putative CLE receptors. Plant Biotechnol J. 2015;13:80110.

Ha BK, Robbins RT, Han F, Hussey RS, Soper JF, Boerma HR. SSR mapping and confirmation of soybean QTL from PI 437654 conditioning resistance to reniform nematode. Crop Sci. 2007:47:1336-43.

Han Y, Zhao X, Cao G, Wang Y, Li Y, Liu D, et al. Genetic characteristics of soybean resistance to $\mathrm{HG}$ type 0 and $\mathrm{HG}$ type 1.2.3.5.7 of the cyst nematode analyzed by genome-wide association mapping. BMC Genomics. 2015;16:598.

Hu Y, You J, Li C, Pan F, Wang C. The Heterodera glycines effector Hg16B09 is required for nematode parasitism and suppresses plant defense response. Plant Sci. 2019;289:110271. https://doi.org/10.1016/j.plantsci.2019.110271.

Hua C, Li C, Hu Y, Mao Y, You J, Wang M, et al. Identification of HG types of soybean cyst nematode Heterodera glycines and resistance screening on soybean genotypes in Northeast China. J Nematol. 2018;50:41-50.

Jiang H, Bu F, Tian L, Sun Q, Bao D, Zhao X, et al. RNA-Seq-based identification of potential resistance mechanism against the soybean cyst nematode (Heterodera glycines) HG type 0 in soybean (Glycine max) cv. Dongnong L204. Crop Pasture Sci. 2020;71(6):539-51. https://doi.org/10.1071/CP20060.

Jiao Y, Vuong TD, Liu Y, Li Z, Noe J, Robbins RT, et al. Identification of quantitative trait loci underlying resistance to southern root-knot and reniform nematodes in soybean accession PI 567516C. Mol Breed. 2015a;35: 131.

Jiao Y, Vuong TD, Liu Y, Meinhardt C, Liu Y, Joshi T, et al. Identification and evaluation of quantitative trait loci underlying resistance to multiple $\mathrm{HG}$ types of soybean cyst nematode in soybean PI 437655. Theor Appl Genet. 2015b;128:15-23.

Juvale PS, Baum TJ. "Cyst-ained" research into Heterodera parasitism. PLoS Pathog. 2018;14:e1006791.

Kadam S, Vuong TD, Qiu D, Meinhardt CG, Song L, Deshmukh R, et al. Genomicassisted phylogenetic analysis and marker development for next generation soybean cyst nematode resistance breeding. Plant Sci. 2016;242:342-50.

Kandoth PK, Ithal N, Recknor J, Maier T, Nettleton D, Baum TJ, et al. The soybean Rhgl locus for resistance to the soybean cyst nematode Heterdera glycines regulates the expression of a large number of stress- and defense-related genes in degenerating feeding cells. Plant Physiol. 2011;155:1960-75.
Kandoth PK, Liu S, Prenger E, Ludwig A, Lakhssassi N, Heinz R, et al. Systematic mutagenesis of serine hydroxymethyltransferase reveals an essential role in nematode resistance. Plant Physiol. 2017;175:1370-80.

Kang H, Eun G, Ha J, Kim Y, Park N, Kim D, et al. New cyst nematode, Heterodera sojae n. sp. (Nematoda: Heteroderidae) from soybean in Korea. J Nematol. 2016:48:280-9.

Karosick DA, Kandoth PK, Tanner JJ, Mitchum MG, Beamer LJ. Impaired folate binding of serine hydroxymethyltransferase 8 from soybean underlies resistance to the soybean cyst nematode. J Biol Chem. 2020;295:3708-18.

Kazi S, Shultz J, Afzal J, Hashmi R, Jasim M, Bond J, et al. Iso-lines and inbred-lines confirmed loci that underlie resistance from cultivar 'Hartwig' to three soybean cyst nematode populations. Theor Appl Genet. 2010;120:633-44.

Kikuchi T, Aikawa T, Oeda Y, Karim N, Kanzaki N. A rapid and precise diagnostic method for detecting the pinewood nematode Bursaphelenchus xylophilus by loop-mediated isothermal amplification. Phytopathology. 2009;99:1365-9.

Kim KS, Vuong TD, Qiu D, Robbins RT, Shannon GJ, Li Z, et al. Advancements in breeding, genetics, and genomics for resistance to three nematode species in soybean. Theor Appl Genet. 2016;129:2295-311.

Kim M, Diers BW. Fine mapping of the SCN resistance QTL caSCN-006 and caSCN007 from Glycine soja PI 468916. Crop Sci. 2013;53:775-85.

Kim M, Hyten DL, Bent AF, Diers BW. Fine mapping of the SCN resistance locus rhg1-b from PI88788. Plant Genome. 2010;3:81-9.

Kim M, Hyten DL, Niblack TL, Diers BW. Stacking resistance alleles from wild and domestic soybean sources improves soybean cyst nematode resistance. Crop Sci. 2011;51:934-43.

Klink VP, Hosseini P, Matsye P, Alkharouf NW, Matthews BF. A gene expression analysis of syncytia laser microdissected from the roots of the Glycine max (soybean) genotype PI 548402 (Peking) undergoing a resistant reaction after infection by Heterodera glycines (soybean cyst nematode). Plant Mol Biol. 2009;71:525-67.

Klink VP, Overall CC, Alkharouf NW, MacDonald MH, Matthews BF. Laser capture microdissection (LCM) and comparative microarray expression analysis of syncytial cells isolated from incompatible and compatible soybean (Glycine max) roots infected by the soybean cyst nematode (Heterodera glycines). Planta. 2007a;226:1389-409.

Klink VP, Overall CC, Alkharouf NW, MacDonald MH, Matthews BF. A time-course comparative microarray analysis of an incompatible and compatible response by Glycine max (soybean) to Heterodera glycines (soybean cyst nematode) infection. Planta. 2007b;226:1423-47.

Koenning SR, Wrather JA. Suppression of soybean yield potential in the continental United States from plant diseases estimated from 2006 to 2009. Plant Health Progress. 2010;11(1):5. https://doi.org/10.1094/PHP-2010-1122-01-RS.

Kong XC, Li HM, Geng T, Huang WK, Peng DL. Resistance evaluation of soybean varieties and germplasms to the races no. 3 and no.4 of soybean cyst nematode Heterodera glycines. Plant Prot. 2012;38:146-50 (in Chinese).

Lakhssassi N, Liu S, Bekal S, Zhou Z, Colantonio V, Lambert K, et al. Characterization of the soluble NSF attachment protein gene family identifies two members involved in additive resistance to a plant pathogen. Sci Rep. 2017;7:45226.

Lakhssassi N, Piya S, Bekal S, Liu S, Zhou Z, Bergounioux C, et al. A pathogenesisrelated protein GmPR10-bet VI promotes a molecular interaction between the GmSHMT08 and GmSNAP18 in resistance to Heterodera glycines. Plant Biotechnol J. 2020;18:1810-29.

Lawaju BR, Niraula P, Lawrence GW, Lawrence KS, Klink VP. The Glycine max conserved oligomeric Golgi (COG) complex functions during a defense response to Heterodera glycines. Front Plant Sci. 2020;11:564495. https://doi. org/10.3389/fpls.2020.564495.

Lee TG, Kumar I, Diers BW, Hudson ME. Evolution and selection of Rhg1, a copynumber variant nematode-resistance locus. Mol Ecol. 2015;24:1774-91.

Li K, Liu ZT, Li HC, Zhang K, Wang CK, Ren R, et al. Resistance to soybean mosaic virus and soybean cyst nematode of soybean cultivars from China National Soybean Uniform Trials. Soybean Sci. 2013;32(5):670-5 (in Chinese). http:// ddkx.haasep.cn/oa/DArticle.aspx?type=view\&id $=201305019$.

Li MS, Yu W, Qu HT, Zhang CH, Zhao L, Wei DX, et al. Evaluation of resistance of soybean germplasm to race 3 of soybean cyst nematode. Soybean Sci. 2017; 36(5):778-81 (in Chinese). http://ddkx.haasep.cn/oa/DArticle.aspx?type= view\&id=201705018.

Lian Y, Guo J, Li H, Wu Y, Wei H, Wang J, et al. A new race (X12) of soybean cyst nematode in China. J Nematol. 2017;49:321-6.

Lian Y, Wang JS, Wei H, Li JY, Gong GM, Wang SF, et al. Distribution survey of soybean cyst nematode of new race X12 in Gujiao City, Shanxi Province. 
Acta Agron Sin. 2021;47:237-44 (in Chinese). https://doi.org/10.3724/SP.J.1 006.2021.04111.

Lian Y, Wei H, Wang J, Lei C, Li H, Li J, et al. Chromosome-level reference genome of $\mathrm{X} 12$, a highly virulent race of the soybean cyst nematode Heterodera glycines. Mol Ecol Resour. 2019;19:1637-46.

Lin J, Mazarei M, Zhao N, Zhu JJ, Zhuang X, Liu W, et al. Overexpression of a soybean salicylic acid methyltransferase gene confers resistance to soybean cyst nematode. Plant Biotechnol J. 2013;11:1135-45.

Liu CJ, Cao CX, Zhou RH, Cheng XL. Field tests of Bacillus thuringiensis for controlling Heterodera glycines Ichinohe. Hubei Agric Sci. 2011a;50:520-2 (in Chinese). http://en.cnki.com.cn/Article_en/CJFDTOTAL-HBNY201103029.htm.

Liu M, Li W, Liu M, Xiao JL, Bi YD, Li W, et al. Screening of control methods in soybean cyst nematode. Soybean Sci. 2014;33(4):566-9 (in Chinese). http:// ddkx.haasep.cn/oa/DArticle.aspx?type=view\&id=201404021.

Liu S, Ge F, Huang W, Lightfoot DA, Peng D. Effective identification of soybean candidate genes involved in resistance to soybean cyst nematode via direct whole genome re-sequencing of two segregating mutants. Theor Appl Genet. 2019;132:2677-87.

Liu S, Kandoth PK, Lakhssassi N, Kang J, Colantonio V, Heinz R, et al. The soybean GmSNAP18 gene underlies two types of resistance to soybean cyst nematode. Nat Commun. 2017:8:14822.

Liu S, Kandoth PK, Warren SD, Yeckel G, Heinz R, Alden J, et al. A soybean cyst nematode resistance gene points to a new mechanism of plant resistance to pathogens. Nature. 2012;492:256-60.

Liu SS, Yang Q, Jian H. Resistance evaluation of soybean germplasms to soybean cyst nematodes. Acta Phytopathol Sin. 2015;45(3):317-25 (in Chinese). http:// zwblxb.magtech.com.cn/CN/abstract/abstract580.shtml.

Liu WZ, Liu Y, Duan YX, Hong QC, Wang KN. Studies on the soybean cyst nematode (Heterodera glycines) in China. Korean J Appl Entomol. 1995;34:838.

Liu X, Liu S, Jamai A, Bendahmane A, Lightfoot DA, Mitchum MG, et al. Soybean cyst nematode resistance in soybean is independent of the Rhg 4 locus LRRRLK gene. Funct Integr Genomics. 2011b;11(4):539-49. https://doi.org/10.1 007/s10142-011-0225-4.

Liu XZ, Li JQ, Zhang DS. History and status of soybean cyst nematode in China. Int J Nematol. 1997;7:18-25.

Liu ZX, Lu WG, Chang RZ, Qiu LJ. Creation of new soybean SCN4-resistant lines. Soybean Sci. 2008;27(6):911-4 (in Chinese). http://ddkx.haasep.cn/oa/DA rticle.aspx?type=view\&id $=200806002$

Long HB, Chen W, Pei YL, Feng TZ, Sun YF. Occurrence and distribution of Heterodera glycines in Guizhou Province. Plant Prot. 2017:43:173-6 (in Chinese). http://en.cnki.com.cn/Article_en/CJFDTotal-ZWBH201706033.htm.

Luo N, Li HX, Guo Y, Xu PG, Zhang SL, Liu YG. Occurrence and distribution of Heterodera glycines in southeast of Gansu, Province. Plant Prot. 2019;45:165-9 (in Chinese). https://en.cnki.com.cn/Article_en/CJFDTotal-ZWBH201903030. htm.

Luo N, Liu YG, Li HX, Li HY, Chen XJ. Control effect of several nematicides on soybean cyst nematode in Gansu Province. Shaanxi J Agric Sci. 2020;66:10-4 (in Chinese).

Ma YS, Liu XL, Luan XY, Wang JJ, Li JR, Yu BS, et al. Identification efficiency about resistance to soybean cyst nematode with relative molecular markers in hybrid progeny. 2015. Soybean Sci. 2014;33(2):173-8 (in Chinese). http://ddkx. haasep.cn/oa/DArticle.aspx?type=view\&id=201402005.

Ma YS, Wang WH, Wang LX, Ma FM, Wang PW, Chang RZ, et al. Genetic diversity of soybean and the establishment of a core collection focused on resistance to soybean cyst nematode. J Integr Plant Biol. 2006;48:722-31.

Mahalingam R, Shorupska HT. DNA markers for resistance to Heterodera glycines.1. Race 3 in soybean cultivar Peking. Breed Sci. 1995;45:435-43.

Masonbrink R, Maier TR, Muppirala U, Seetharam AS, Lord E, Juvale PS, et al. The genome of the soybean cyst nematode (Heterodera glycines) reveals complex patterns of duplications involved in the evolution of parasitism genes. BMC Genomics. 2019;20:119.

Matsye PD, Kumar R, Hosseini P, Jones CM, Tremblay A, Alkharouf NW, et al. Mapping cell fate decisions that occur during soybean defense responses. Plant Mol Biol. 2011;77(4-5):513-28. https://doi.org/10.1007/s11103-011-9828-3.

Matsye PD, Lawrence GW, Youssef RM, Kim KH, Lawrence KS, Matthews BF, et al. The expression of a naturally occurring, truncated allele of an a-SNAP gene suppresses plant parasitic nematode infection. Plant Mol Biol. 2012;80:13155.

Matthews BF, Beard H, Brewer E, Kabir S, MacDonald MH, Youssef RM. Arabidopsis genes, AtNPR1, AtTGA2 and AtPR-5, confer partial resistance to soybean cyst nematode (Heterodera glycines) when overexpressed in transgenic soybean roots. BMC Plant Biol. 2014;14(1):96. https://doi.org/10.1186/1471-2229-14-96.

Matthews BF, Beard H, MacDonald MH, Kabir S, Youssef RM, Hosseini P, et al. Engineered resistance and hypersusceptibility through functional metabolic studies of 100 genes in soybean to its major pathogen, the soybean cyst nematode. Planta. 2013;237:1337-57.

Meksem K, Pantazopoulos P, Njiti VN, Hyten LD, Arelli PR, Lightfoot DA. 'Forrest' resistance to the soybean cyst nematode is bigenic: saturation mapping of the Rhg1 and Rhg4 loci. Theor Appl Genet. 2001;103(5):710-7. https://doi. org/10.1007/s001220100597.

Melito S, Heuberger AL, Cook D, Diers BW, MacGuidwin AE, Bent AF. A nematode demographics assay in transgenic roots reveals no significant impacts of the Rhg1 locus LRR-kinase on soybean cyst nematode resistance. BMC Plant Biol. 2010;10(1):104. https://doi.org/10.1186/1471-2229-10-104.

Mitchum MG. Soybean resistance to the soybean cyst nematode Heterodera glycines: an update. Phytopathology. 2016;106:1444-50.

Mitchum MG, Wrather JA, Heinz RD, Shannon JG, Danekas G. Variability in distribution and virulence phenotypes of Heterodera glycines in Missouri during 2005. Plant Dis. 2007;91(11):1473-6. https://doi.org/10.1094/PDIS91-11-1473.

Nan HY, Li YH, Chang RZ, Qiu LJ. Development and identification of InDel markers based on rhgl gene for resistance to soybean cyst nematode (Heterodera glycines Ichinohe). Acta Agron Sin. 2009;35(7):1236-43 (in Chinese). https://doi.org/10.3724/SP.J.1006.2009.01236.

Ngaki MN, Sahoo DK, Wang B, Bhattacharyya MK. Overexpression of a plasma membrane protein generated broad-spectrum immunity in soybean. Plant Biotechnol J. 2021;19:502-16.

Niblack TL, Arelli PR, Noel GR, Opperman CH, Orf JH, Schmitt DP, et al. A revised classification scheme for genetically diverse populations of Heterodera glycines. J Nematol. 2002;34(4):279-88.

Ou S, Peng D, Liu X, Li Y, Moens M. Identification of Heterodera glycines using PCR with sequence characterized amplified region (SCAR) primers. Nematology. 2008;10:397-403.

Pant SR, Krishnavajhala A, McNeece BT, Lawrence GW, Klink VP. The syntaxin 31induced gene, LESION SIMULATING DISEASE1 (LSD1), functions in Glycine max defense to the root parasite Heterodera glycines. Plant Signal Behav. 2015;10:e977737.

Pant SR, Matsye PD, McNeece BT, Sharma K, Krishnavajhala A, Lawrence GW, et al. Syntaxin 31 functions in Glycine max resistance to the plant parasitic nematode Heterodera glycines. Plant Mol Biol. 2014;85:107-21.

Patil GB, Lakhssassi N, Wan J, Song L, Zhou Z, Klepadlo M, et al. Whole-genome re-sequencing reveals the impact of the interaction of copy number variants of the rhgl and Rhg4 genes on broad-based resistance to soybean cyst nematode. Plant Biotechnol J. 2019;17:1595-611.

Peng DL. Race variation of soybean cyst nematode stressed by resistant varieties. In: Zhu YY, Li JQ, Wang HM, editors. Advanced in plant pathology. Kunming: Yunnan Sciences and Technology Press; 1999. p. 91-4. (in Chinese).

Peng DL, Peng H, Wu DQ, Huang WK, Ye WX, Cui JK. First report of soybean cyst nematode (Heterodera glycines) on soybean from Gansu and Ningxia China. Plant Dis. 2016a;100(1):229. https://doi.org/10.1094/PDIS-04-15-0451-PDN.

Peng DL, Subbotin SA, Moens M, Tang WH. A rapid method for the diagnosis of soybean cyst nematode (Heterodera glycines) using duplex PCR. J Shenyang Agric Univ. 2001;32:216-7 (in Chinese). http://en.cnki.com.cn/Article_en/ CJFDTOTAL-SYNY200103015.htm.

Peng H, Cui JK, Long HB, Huang WK, Kong LA, Liu SM, et al. Novel pectate lyase genes of Heterodera glycines play key roles in the early stage of parasitism. PLoS One. 2016b;11(3):e0149959. https://doi.org/10.1371/journal.pone.0149959.

Peng H, Long HB, Huang WK, Liu J, Cui JK, Kong LA, et al. Rapid, simple and direct detection of Meloidogyne hapla from infected root galls using loopmediated isothermal amplification combined with FTA technology. Sci Rep. 2017;7(1):44853. https://doi.org/10.1038/srep44853.

Peng H, Peng D, Hu X, He X, Wang Q, Huang W, et al. Loop-mediated isothermal amplification for rapid and precise detection of the burrowing nematode, Radopholus similis, directly from diseased plant tissues. Nematology. 2012a;14:977-86.

Peng H, Peng DL, Huang WK, He WT, Hu XQ. Molecular cloning and analysis of a novel pectate lyase gene hg-pel-5 from soybean cyst nematode. Sci Agric Sin. 2012b;45:854-66 (in Chinese). https://doi.org/10.3864/j.issn.0578-1752.2 012.05.005.

Peng H, Qi X, Peng D, Long H, He X, Huang W, et al. Sensitive and direct detection of Heterodera filipjevi in soil and wheat roots by species-specific SCAR-PCR assays. Plant Dis. 2013;97:1288-94. 
Popeijus H, Overmars H, Jones J, Blok V, Goverse A, Helder J, et al. Degradation of plant cell walls by a nematode. Nature. 2000;406:36-7.

Rambani A, Pantalone V, Yang S, Rice JH, Song Q, Mazarei M, et al. Identification of introduced and stably inherited DNA methylation variants in soybean associated with soybean cyst nematode parasitism. New Phytol. 2020;227:168-84.

Rambani A, Rice JH, Liu J, Lane T, Ranjan P, Mazarei M, et al. The methylome of soybean roots during the compatible interaction with the soybean cyst nematode. Plant Physiol. 2015;168:1364-77.

Riggs RD, Niblack TL. Nematode pest of oilseed crops and grain legumes. In: Evans K, Trudgill DL, Webster JM, editors. Plant parasitic nematodes in temperate agriculture. Wallingford: CAB International; 1993. p. 209-58.

Riggs RD, Schmitt DP. Complete characterization of the race scheme for Heterodera glycines. J Nematol. 1988;20:392-5.

Ruben E, Jamai A, Afzal J, Njiti VN, Triwitayakorn K, Iqbal MJ, et al. Genomic analysis of the rhg1 locus: candidate genes that underlie soybean resistance to the cyst nematode. Mol Gen Genomics. 2006;285:355-6.

Shi XH, Li YH, Yu BS, Guo Y, Wang JJ, Qiu LJ. Development and utilization of CAPS/dCAPS markers based on the SNPs lying in soybean cyst nematode resistant genes Rhg4. Acta Agron Sin. 2015a;41:1463-71 (in Chinese). https:// doi.org/10.3724/SP.J.1006.2015.01463.

Shi Z, Liu S, Noe J, Arelli P, Meksem K, Li Z. SNP identification and marker assay development for high-throughput selection of soybean cyst nematode resistance. BMC Genomics. 2015b;16(1):314. https://doi.org/10.1186/s12864-015-1531-3.

Singh SK, Hodda M, Ash GJ, Banks NC. Plant-parasitic nematodes as invasive species: characteristics, uncertainty and biosecurity implications. Ann Appl Biol. 2013;163:323-50.

Song MJ, Zhu XF, Wang D, Wang YY, Chen LJ, Liu XY, et al. Population distribution and pathogenicity differentiation of soybean cyst nematode in main soybean production areas of China. Soybean Sci. 2016:35(4):630-6 (in Chinese). http://ddkx.haasep.cn/oa/DArticle.aspx?type=view\&id=201604018.

Ste-Croix DT, St-Marseille AG, Lord E, Belanger RR, Brodeur J, Mimee B. Genomic profiling of virulence in the soybean cyst nematode using single-nematode sequencing. Phytopathology. 2021;111(1):137-48. https://doi.org/10.1094/ PHYTO-08-20-0348-FI.

Subbotin SA, Peng DL, Moens M. A rapid method for the identification of the soybean cyst nematode Heterodera glycines using duplex PCR. Nematology. 2001;3:365-71.

Suzuki C, Taguchi-Shiobara F, Ikeda C, Iwahashi M, Matsui T, Yamashita Y, et al. Mapping soybean rhg2 locus, which confers resistance to soybean cyst nematode race 1 in combination with rhg 1 and Rhg 4 derived from PI 84751. Breed Sci. 2020;70:474-80

Tian B, Yang J, Zhang KQ. Bacteria used in the biological control of plant-parasitic nematodes: populations, mechanisms of action, and future prospects. FEMS Microbiol Ecol. 2007;61(2):197-213. https://doi.org/10.1111/j.1574-6941.2007.00349x.

Tian Y, Liu B, Shi X, Reif JC, Guan R, Li YH, et al. Deep genotyping of the gene GmSNAP facilitates pyramiding resistance to cyst nematode in soybean. Crop J. 2019;7:677-84.

Tian Y, Yang L, Li YH, Qiu LJ. Development and utilization of KASP marker for SCN3-11 locus resistant to soybean cyst nematode. Acta Agron Sin. 2018;44: 1600-11 (in Chinese). https://doi.org/10.3724/SP.J.1006.2018.01600.

Usovsky M, Ye H, Vuong TD, Patil GB, Wan J, Zhou L, et al. Fine-mapping and characterization of aSCN18, a novel QTL controlling soybean cyst nematode resistance in PI 567516C. Theor Appl Genet. 2021;134:621-31.

Vieira P, Gleason C. Plant-parasitic nematode effectors-insights into their diversity and new tools for their identification. Curr Opin Plant Biol. 2019:50:37-43.

Vuong TD, Sleper DA, Shannon JG, Nguyen HT. Novel quantitative trait loci for broad-based resistance to soybean cyst nematode (Heterodera glycines Ichinohe) in soybean PI 567516C. Theor Appl Genet. 2010;121: 1253-66

Vuong TD, Sonah H, Meinhardt CG, Deshmukh R, Kadam S, Nelson RL, et al. Genetic architecture of cyst nematode resistance revealed by genome-wide association study insoybean. BMC Genomics. 2015;16:593.

Wang D, Diers BW, Arelli PR, Shoemaker RC. Loci underlying resistance to race 3 of soybean cyst nematode in Glycine soja plant introduction 468916. Theor Appl Genet. 2001;103(4):561-6. https://doi.org/10.1007/PL00002910.

Wang D, Duan YX, Wang YY, Zhu XF, Chen LJ, Liu XY, et al. First report of soybean cyst nematode, Heterodera glycines, on soybean from Guangxi, Guizhou, and Jiangxi provinces, China. Plant Dis. 2015;99:893.

Wang K, Riggs RD, Crippen D. Competition between two phenotypes of the nematophagous fungus ARF in infecting eggs of Heterodera glycines and effect of soil depth on parasitism by ARF. Nematology. 2004;6:329-34
Wang L, Zhou J, Li W, Yu JQ, Lai YC, Liu M, et al. Effect of new agents on Heterodera glycines control and yield of soybean. Soybean Sci. 2017;36(6):943-9 (in Chinese). http://ddkx.haasep.cn/oa/DArticle.aspx?type=view\&id=201706023.

Wang LZ, Zhao RJ, Wang L, Yan QS, Chen PS, Li Q. Study on soybean breeding for resistance to cyst nematode. Sci Agric Sin. 2002;35:476-81 (in Chinese). https://www.chinaagrisci.com/CN/Y2002/N35/15/476.

Wang N, Peng H, Liu SM, Huang WK, Holgado R, Clarke JL, et al. Molecular characterization and functional analysis of two new lysozyme genes from soybean cyst nematode (Heterodera glycines). J Integr Agric. 2019;18(12): 2806-13. https://doi.org/10.1016/S2095-3119(19)62766-8.

Webb DM, Baltazar BM, Rao-Arelli AP, Schupp J, Clayton K, Keim P, et al. Genetic mapping of soybean cyst nematode race 3 resistance loci in the soybean PI 437654. Theor Appl Genet. 1995;91:574-81.

Winter SMJ, Rajcan I, Shelp BJ. Soybean cyst nematode: challenges and opportunities. Can J Plant Sci. 2006;86:25-32

Winter SMJ, Shelp BJ, Anderson TR, Welacky TW, Rajcan I. QTL associated with horizontal resistance to soybean cyst nematode in Glycine soja PI464925B. Theor Appl Genet. 2007;114:461-72.

Woo MO, Beard H, MacDonald MH, Brewer EP, Youssef RM, Kim H, et al. Manipulation of two a-endo- $\beta-1,4$-glucanase genes, AtCel6 and GmCel7, reduces susceptibility to Heterodera glycines in soybean roots. Mol Plant Pathol. 2014;15:927-39.

Wu X, Blake S, Sleper DA, Shannon JG, Cregan P, Nguyen HT. QTL, additive and epistatic effects for SCN resistance in PI 437654. Theor Appl Genet. 2009;118:1093-105.

Yang L, Tian Y, Liu Y, Reif JC, Li Y, Qiu L. QTL mapping of aSCN3-1 for resistance to soybean cyst nematode in soybean line Zhongpin 03-5373. Crop J. 2021; 9(2):351-9. https://doi.org/10.1016/j.cj.2020.08.003.

Yang Y, Zhou Y, Chi Y, Fan B, Chen Z. Characterization of soybean WRKY gene family and identification of soybean WRKY genes that promote resistance to soybean cyst nematode. Sci Rep. 2017;7:17804.

Youssef RM, MacDonald MH, Brewer EP, Bauchan GR, Kim KH, Matthews BF Ectopic expression of AtPAD4 broadens resistance of soybean to soybean cyst and root-knot nematodes. BMC Plant Biol. 2013;13:67.

Yu N, Diers BW. Fine mapping of the SCN resistance QTL caSCN-006 and caSCN007 from Glycine soja PI 468916. Euphytica. 2017;213:54.

Yu N, Lee TG, Rosa DP, Hudson M, Diers BW. Impact of Rhg 1 copy number, type, and interaction with Rhg4 on resistance to Heterodera glycines in soybean. Theor Appl Genet. 2016;129:2403-12.

Yu WB, Wu YH, Huang JM, Zheng ZX. Research progress on biological control of Heterodera glycines. J Hebei Agric Sci. 2013;17:56-8 99 (in Chinese). http://en. cnki.com.cn/Article_en/CJFDTOTAL-HBKO201305017.htm.

Yuan M, Han DW, Li XY, Wang SR, Yu KC, Wang LX, et al. Effect of Junxianke biological seed coating agent on soybean cyst nematode and yield. Soybean Sci Technol. 2020:5:19-22 (in Chinese). https://kns.cnki.net/KCMS/detail/deta il.aspx?dbcode $=$ CJFD\&filename $=$ DDTB202005004 .

Yue P, Sleper DA, Arelli PR. Mapping resistance to multiple races of Heterodera glycines in soybean PI 89772. Crop Sci. 2001;41(5):1589-95. https://doi.org/1 0.2135/cropsci2001.4151589x.

Zhang YD, Kong XC, Huang WK, Kong LA, Li HM, Peng H, et al. Identification and functional analysis of two expansin genes hg-exp-1 and hg-exp-2 from the soybean cyst nematode (Heterodera glycines). Sci Agric Sin. 2018;51:3302-14 (in Chinese). https://doi.org/10.3864/j.issn.0578-1752.2018.17.006.

Zhen HY, Peng H, Kong LA, Hong BY, Zhu GL, Wang RH, et al. Heterodera sojae, a new cyst nematode record in China and its parasitism to legume crops. Sci Agric Sin. 2018:51:2913-24 (in Chinese). https://doi.org/10.3864/j.issn.0578-1752.2018.15.007.

Zheng J, Zhang Y, Li X, Zhao L, Chen S. First report of the soybean cyst nematode, Heterodera glycines, on soybean in Zhejiang, eastern China. Plant Dis. 2009;93:319.

Zheng JW, Subbotin SA, Waeyenberge L, Moens M. Molecular characterisation of Chinese Heterodera glycines and $H$. avenae populations based on RFLPs and sequences of rDNA-ITS regions. Russ J Nematol. 2000:8:109-13.

Zheng N, Li T, Dittman JD, Su J, Li R, Gassmann W, et al. CRISPR/Cas9-based gene editing using egg cell-specific promoters in Arabidopsis and soybean. Front Plant Sci. 2020;11:800

Zhou L, Song L, Lian Y, Ye H, Usovsky M, Wan J, et al. Genetic characterization of qSCN10 from an exotic soybean accession PI 567516C reveals a novel source conferring broad-spectrum resistance to soybean cyst nematode. Theor Appl Genet. 2021;134(3):859-74. https://doi.org/10.1007/s00122-020-03736-4. 